\title{
RELAÇÃO ENTRE AS ILHAS DE CALOR E USO E OCUPAÇÃO DO SOLO EM CENTROS URBANOS DE PEQUENO PORTE UTILIZANDO O SENSORIAMENTO REMOTO
}

\author{
THE RELATION BETWEEN HEAT ISLANDS AND THE USE AND OCCUPATION OF THE SOIL \\ IN SMALL URBAN CENTERS THROUGH REMOTE SENSING
}

\author{
Cristhy Willy da Silva ROMERO ${ }^{1}$, Helio Ricardo SILVA ${ }^{2}$, Artur Pantoja MARQUES ${ }^{3}$, \\ Fabricio Lopes de MACEDO ${ }^{4}$, Glaucia Amorim FARIA ${ }^{5}$, Marlene Cristina ALVES ${ }^{2}$ \\ ${ }^{1}$ UNICAMP/FEAGRI. Universidade Estadual de Campinas. Faculdade de Engenharia Agrícola. Av. Candido Rondon, 501 - Cidade \\ Universitária. Campinas, SP, Brasil. romero.cws@ gmail.com \\ ${ }^{2}$ UNESP - Universidade Estadual Paulista. Faculdade de Engenharia de Ilha Solteira. Departamento de Fitossanidade e Engenharia \\ Rural. Av. Brasil, 56 - Faculdade de Agronomia. Ilha Solteira, SP, Brasil. E-mails: hr.silva@ unesp.br; glaucia@mat.feis.unesp.br; \\ mcalves@agr.feis.unesp.br \\ ${ }^{3}$ UNESP - Universidade Estadual Paulista. Faculdade de Engenharia de Ilha Solteira. Departamento de Engenharia Civil. Ilha \\ Solteira, SP, Brasil. E-mail: artur.pantoja@unesp.br \\ ${ }^{4}$ Universidade da Madeira, ISOplexis - Centro de Agricultura Sustentável e Tecnologia Alimentar. Funchal, Portugal. \\ E-mail: fabriciolmacedo@hotmail.com \\ ${ }^{5}$ UNESP - Universidade Estadual Paulista, Faculdade de Engenharia de Ilha Solteira, Departamento de Matemática, Laboratório de \\ Estatística Aplicada, Ilha Solteira, SP, Brasil: E-mail: glaucia.a.faria@unesp.br

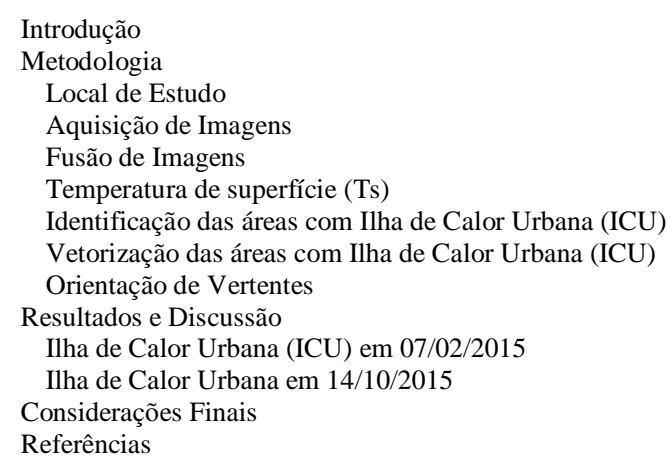

RESUMO - Todos os dias os centros urbanos sofrem com o aumento da temperatura. Diante do aquecimento global, a degradação desses ambientes, traz riscos à saúde da população, desde o desconforto térmico até a ocorrência de doenças causadas pelo calor. Devido ao processo de urbanização, essa mudança na paisagem favorece a ocorrência do fenômeno da ilha de calor urbana (ICU), áreas urbanas com temperaturas mais elevadas que as áreas rurais vizinhas. Este fenômeno é realidade não em grandes municípios, mas também ocorre em cidades pequenas. O objetivo deste trabalho foi analisar a ocorrência de ICU em Ilha Solteira - SP, através do uso de dados de sensoriamento remoto, visando associar uma temperatura superficial com diferentes classes de uso e cobertura da terra. Para o propósito deste trabalho, utilizou-se uma imagem de satélite capturada na região do infravermelho (TIRS / Landsat-8) como classes de uso e ocupação do solo nas áreas de temperaturas mais altas, baseadas em imagens de alta resolução, no satélite Plêiades. Dado que as diferentes classes de uso e ocupação do solo influenciam diretamente a temperatura da superfície, observando-se a pavimentação asfáltica e o telhado cerâmico como valores mais altos de temperatura, nas áreas de ICU das pequenas cidades.

Palavras-chave: Geotecnologia; Aquecimento Global; Infravermelho Termal.

ABSTRACT - Every day urban centers suffer from rising temperatures. Faced with global warming, degradation of these environments, pose risks to the health of the population, from the thermal discomfort to the occurrence of diseases caused by heat. Due to the urbanization process, this change in the landscape favors an occurrence of the phenomenon of the urban heat island (ICU), urban areas with temperatures higher than its surrounding rural areas. This phenomenon is reality not in large municipalities, but also occurs in small cities. The objective of this work was to analyze the occurrence of ICU in Ilha Solteira - SP, was studied through the use of remote sensing data, aiming to associate a surface temperature with different classes of land-use and land-cover. For a purpose of this work, a satellite image captured in the infrared region (TIRS/Landsat-8) were used as land use and occupation classes in the areas of higher temperatures, based on Images of high spatial resolution, in the satellite Pleiades. Given that the different classes of land use and occupation directly influence the surface temperature, observing an asphalt paving and ceramic roof as higher temperature values, in ICU areas in small cities.

Keywords: Geotechnology; Global Warming; Infrared Termal.

\section{INTRODUÇÃ̃O}

O processo de urbanização promove fortes desconforto térmico, o que resulta na queda da impactos no clima local, pois provoca o aumento qualidade de vida da população (Romero, 2016). da temperatura do ar e consequentemente o Lima et al. (2016) afirmam que, o crescimento São Paulo, UNESP, Geociências, v. 39, n. 1, p. 253 - 268, 2020 
das cidades, conjuntamente ao das populações urbanas, introduz novos elementos físicos e químicos na atmosfera, alterando as condições naturais precedentes e originando o clima urbano. Esta afirmação corrobora com Santana (2014), onde, o clima das cidades são os mais afetados por anomalias climáticas.

Segundo Mashiki \& Campos (2013), a utilização de materiais altamente refletivos altera o comportamento da radiação solar incidente na área urbana, resultando em inúmeros microclimas, como as ilhas de calor (ICU). As ilhas de calor são anomalias térmicas caracterizadas pela elevação de temperatura em determinadas áreas e podem ser observadas em várias escalas (Romero, 2016).

As ilhas de calor são formadas em áreas urbanas e suburbanas, devido os materiais de construção absorverem e reterem maior calor do sol, quando comparado aos materiais naturais presentes em áreas que não sofreram processo de urbanização.

De acordo com Mashiki (2012), a ICU configura-se como um fenômeno decorrente do balanço de energia no espaço urbano, que se caracteriza através do acúmulo de calor nas superfícies e consequente elevação da temperatura do ar. É um "oásis inverso", onde o ar e as temperaturas de superfície são mais quentes do que em áreas rurais circundantes (Gartland, 2010).

As principais causas da ICU da atmosfera urbana inferior são: geometria urbana, poluição do ar, emissão de calor a partir dos edifícios, tráfego e metabolismo dos organismos vivos, cobertura do solo e materiais de construção (Barros \& Lombardo, 2016). De acordo com García (1996), a classificação das ilhas de calor varia de: fraca magnitude quando as diferenças entre os pontos oscilam entre $0^{\circ}$ e $2^{\circ} \mathrm{C}$, média magnitude entre $2^{\circ}$ e $4^{\circ} \mathrm{C}$, forte entre $4^{\circ}$ e $6^{\circ} \mathrm{C}$ e muito forte quando as diferenças ultrapassam os $6^{\circ} \mathrm{C}$.

Devido ao desenvolvimento marcante das Geotecnologias (Geoprocessamento e Sensoriamento Remoto) estudos agrícolas e ambientais vêm ampliando seu espaço dentro da pesquisa, para Catelani et al. (2003), essas técnicas constituem hoje, um importante conjunto de ferramentas aplicáveis ao planejamento geográfico, bem como para a obtenção de dados a serem utilizados no planejamento e zoneamento, tanto em níveis regionais quanto municipais

Com a utilização da geotecnologia é possível adquirir conhecimentos sobre a realidade urbana, e acompanhamento de suas áreas, possibilitando estudos e possíveis tomadas de decisões com bases em informações locais, obtidas espacialmente. Corrêa et al. (2016) afirmam que os avanços tecnológicos do sensoriamento remoto contribuíram para o aprimoramento dos estudos do fenômeno denominado ilha de calor, devido a melhorias consideráveis na resolução espacial, espectral e temporal dos dados.

Atualmente a utilização do sensoriamento remoto vem ganhando espaço em diversos níveis de pesquisa na área ambiental e agronômica, devido à disponibilidade de imagens com médias e altas resoluções, que auxiliam na tomada de decisões de maneira bastante eficaz (Mashiki, 2012).

Nas últimas décadas, o sensoriamento remoto aplicado em estudos de clima urbano vem destacando-se, pois, além de possuir alta resolução espacial e oferecer visões em diferentes escalas, permite a utilização de dados espectrais localizados na região do infravermelho termal dentro da janela atmosférica (Romero, 2016).

Os sensores que operam na região do termal, podem ter seus dados convertidos em temperatura da superfície, após a efetivação das correções dos efeitos atmosféricos e da superfície (emissividade) (Weng \& Yang, 2004), a qual é um parâmetro de importância fundamental para o estudo da climatologia urbana (Voogt \& Oke, 2003).

Para o estudo e estimativa da temperatura aparente da superfície a região do infravermelho utilizada é o termal, pois trata-se de um intervalo que consegue detectar a concentração de fluxo radiante de um material, proveniente das vibrações moleculares decorrente da temperatura radiante dos corpos (Mashiki, 2012).

De acordo com Coelho \& Correa (2013), a obtenção de informações de temperatura da superfície do canal infravermelho termal do sensor TIRS/Landsat 8, banda 10, com utilização da geotecnologia, contribuem na identificação, espacialização e na compreensão da dinâmica climática de microclimas locais.

O objetivo deste trabalho, foi realizar a identificação das ilhas de calor urbana em um município de pequeno porte, Ilha Solteira - SP, verificando a relação de suas ocorrências com as classes de uso e ocupação do solo, associados a dados climatológicos e orientação de vertente. 


\section{METODOLOGIA}

\section{Local de Estudo}

O município de Ilha Solteira está localizado a noroeste do estado de São Paulo, apresentando área total de $661,3 \mathrm{~km}^{2}$, desse total, $5,82 \mathrm{~km}^{2}$ compõem a área urbana (Miranda et al., 2005; Silva et al., 2006). De acordo com o Sistema Internacional de Köeppen, o clima desta região é o tropical úmido, com estação chuvosa no verão e seca no inverno (Aw). As temperaturas médias mensais variam entre $21,5^{\circ} \mathrm{C}$ e $26,4^{\circ} \mathrm{C}$, e as precipitações médias mensais variam de $20 \mathrm{~mm}$ a $225 \mathrm{~mm}$ (Hernandez, 2007).

O relevo da área de estudo é o colinoso, com predomínio de colinas amplas e médias (São Paulo, 1981). Mais de $80 \%$ da área urbana apresenta declividades que variam de 0 a $5 \%$, e as classes de orientações de vertentes que predominam são as sul-oeste (SW) e oeste (W) (Santos, 2005). O solo presente é classificado como Latossolo Vermelho distrófico A moderado de textura argilosa (Embrapa, 1999).

Em Ilha Solteira, existem as áreas verdes denominadas Área de Lazer, localizada na posição norte do perímetro urbano, com 11,35ha, ocupada com a espécie Pinus elliottii; já na posição oeste do perímetro urbano localiza-se o Zoológico abrangendo uma área de 18ha, composta com vegetação predominante do bioma Mata Atlântica (Mata Seca Semi-Decídual) (Costa et al., 2010). A Figura 1 apresenta a localização do município de Ilha Solteira no estado de São Paulo e o limite da área urbana dentro do município.

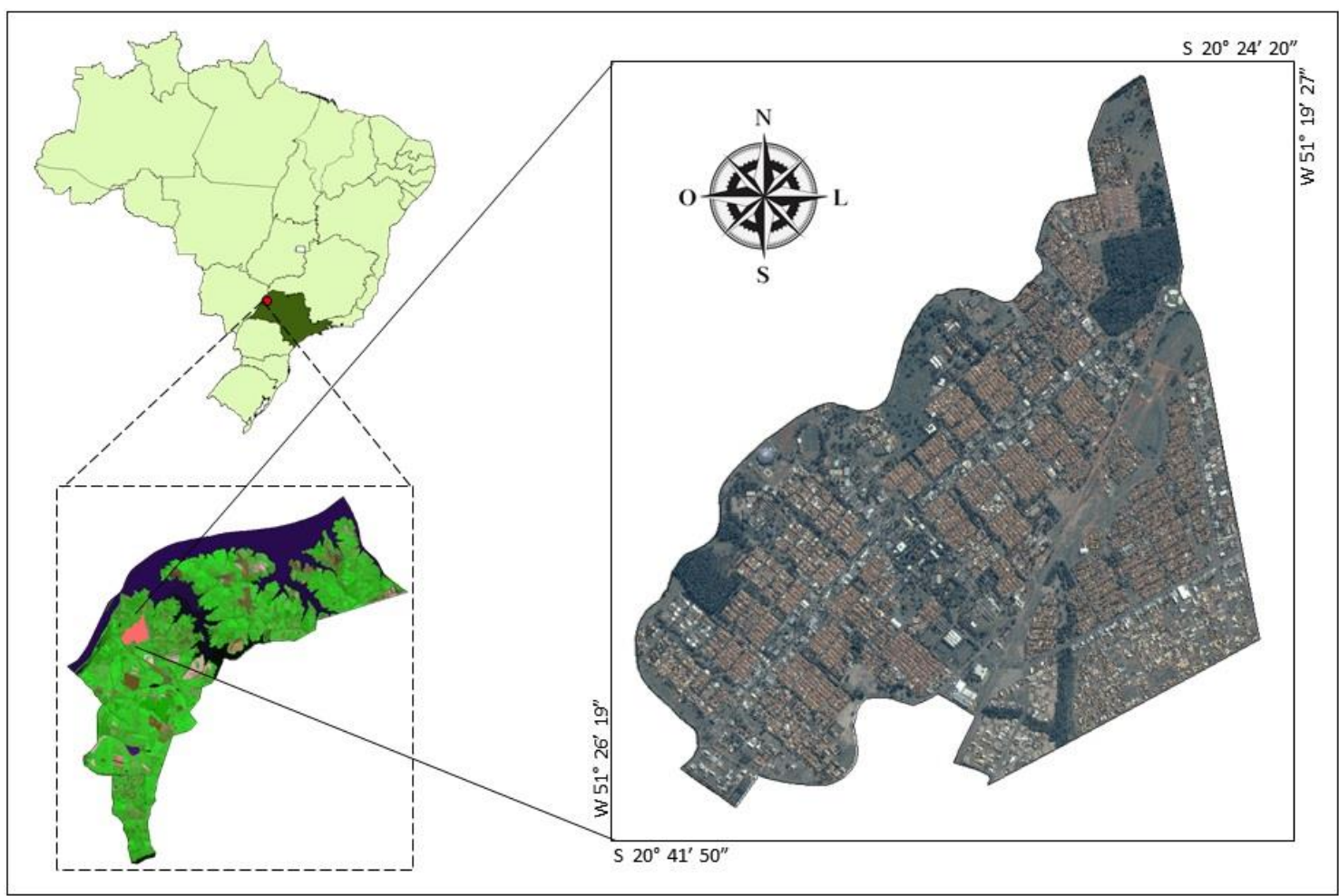

Figura 1 - Mapa de localização da área urbana de Ilha Solteira - SP.

\section{Softwares utilizados}

Para a obtenção da imagem de temperatura de superfície, foi utilizado o SIG QGIS (versão 2.14.3), software livre, licenciado pela General Public License (GNU), projeto oficial da Open Source Geospatial Foundation (OSGeo), obtido em www.qgis.org. Para realização das demais etapas do processamento de dados foi utilizado o SIG SPRING/INPE (versão 5.2.6), disponível em www.dpi.inpe.br/spring. Para a correção de dados vetoriais, como as vias de acesso no interior da área urbana de Ilha Solteira, foi utilizado o software AutoCAD (www.auto desk.com/education/freesoftware/autocad).

\section{Aquisição de Imagens}

Foi realizado um levantamento de imagens orbitais gratuitas, disponíveis em United States Geological Survey (USGS) (www.usgs.gov), oriundas do satélite Landsat 8, sensor TIRS (Thermal Infrared Sensor). Foram escolhidas as imagens livres de cobertura de nuvens (Tabela 1).

As imagens oriundas do Satélite Landsat 8 já são obtidas ortorretificadas com projeção WGS-84, seu horário de passagem é às 10:00, horário local. Para a obtenção de melhores resultados no estudo ligado ao uso e ocupação do solo da área urbana de 
Ilha Solteira, utilizou-se uma imagem do Satélite Pléiades, com alta resolução espacial, $0,50 \mathrm{~m}$, com data de passagem em 03/08/2013, ás 10:00 horas, horário local.

Tabela 1 - Imagens obtidas do satélite Landsat 8.

\begin{tabular}{c|c|c}
\hline & Data da imagem & Orbita/Ponto \\
\hline $\mathbf{1}$ & $15 / 01 / 2015$ & $222 / 074$ \\
\hline $\mathbf{2}$ & $07 / 02 / 2015$ & $222 / 073$ \\
\hline $\mathbf{3}$ & $11 / 03 / 2015$ & $222 / 073$ \\
\hline $\mathbf{4}$ & $21 / 04 / 2015$ & $222 / 074$ \\
\hline $\mathbf{5}$ & $07 / 05 / 2015$ & $222 / 074$ \\
\hline $\mathbf{6}$ & $08 / 06 / 2015$ & $222 / 074$ \\
\hline $\mathbf{7}$ & $10 / 07 / 2015$ & $222 / 074$ \\
\hline $\mathbf{8}$ & $11 / 08 / 2015$ & $222 / 074$ \\
\hline $\mathbf{9}$ & $03 / 09 / 2015$ & $222 / 073$ \\
\hline $\mathbf{1 0}$ & $14 / 10 / 2015$ & $222 / 074$ \\
\hline $\mathbf{1 1}$ & $15 / 01 / 2015$ & $222 / 074$ \\
\hline
\end{tabular}

O limite da área urbana foi com auxílio da planta com as vias de acesso da cidade de Ilha Solteira, em formato digital, cedida pela Prefeitura Municipal

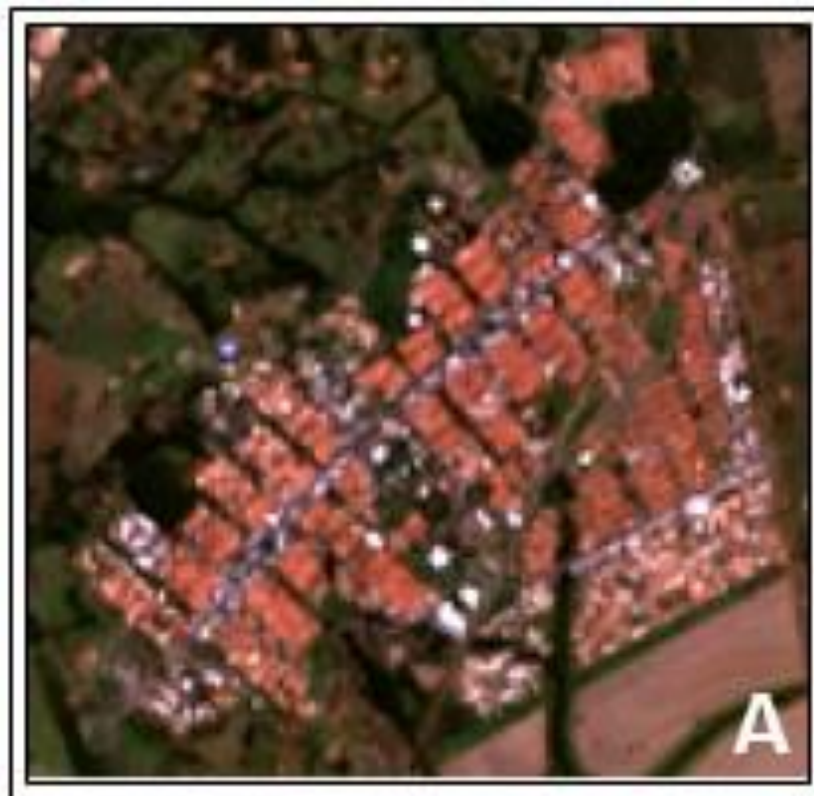

de Ilha Solteira, posteriormente realizou-se algumas correções vetoriais, corrigindo o seu posicionamento, combase na imagem Pléiades que possui alta resolução espacial, e com utilização do software AutoCAD, versão Student (www.auto desk.com/ education/free-software/ autocad).

\section{Fusão de Imagens}

A técnica de fusão de imagens teve como objetivo a integração da banda de melhor resolução espacial, banda 8, pancromática (resolução espacial de $15 \mathrm{~m}$ ), com as bandas de menor resolução, banda 2 a 7 (resolução espacial de 30m). Para o fusionamento de imagens, o método do IHS é um dos mais utilizados, devido a sua eficiência e facilidade de implementação (Tu et al., 2001).

Por se tratar de uma área urbana de pequeno porte, a integração da banda pancromática com as de menor resolução espacial, se torna essencial, pois reúne ambas as características em uma nova imagem, sendo possível a obtenção de uma melhor visualização e interpretação da área de estudo (Figura 2).

Para a geração das imagens fusionadas foi utilizado o SIG livre TerraView/INPE.

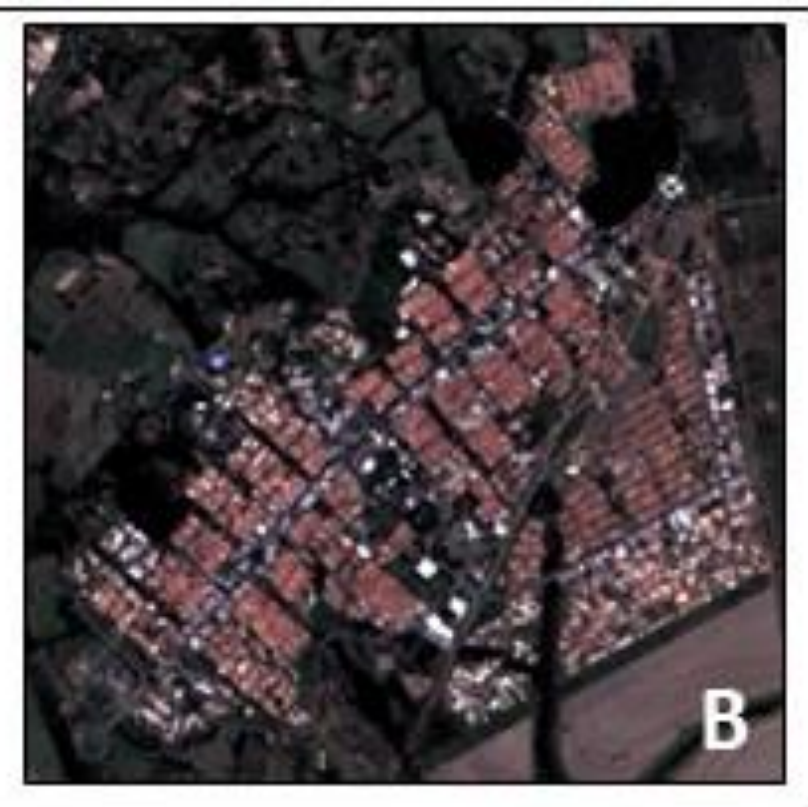

Figura 2 - Comparação de imagem bruta A) e imagem fusionada B).

\section{Temperatura de superfície (Ts)}

A imagem da temperatura de superfície (Ts) foi obtida por meio da banda 10 (termal), do satélite Landsat-8, sensor TIRS, que apresenta a resolução espacial de 30 metros. Para a geração da imagem de temperatura, foi utilizada a ferramenta calculadora raster, ferramenta implementada no SIG QGIS, inserindo a Equação 1, proposta pelo USGS (2015) onde, com base nos metadados contidos no conjunto de imagem, realizou-se a conversão de níveis de cinza para radiância:

$$
L_{\lambda}=M_{L} * Q_{\text {cal }}+A_{L}
$$

em que:

$L_{\lambda}=$ Radiância Espectral no topo da atmosfera em Watts $/\left(\mathrm{m}^{2 *} \mathrm{sr} * \mu \mathrm{m}\right)$

$M_{L}=$ Fator multiplicativo de redimensionamento da banda 10 (3.3420E-04)

$Q_{c a l}=$ Valor quantizado calibrado pelo pixel em DN (banda 10) 
$A_{L}=$ Fator de redimensionamento aditivo especifico da banda 10 (0.10000)

Após a obtenção da imagem de radiância, converteu-se este resultado para imagem de temperatura superfície (Ts), porém a imagem resultante desta conversão apresenta seus dados em temperatura Kelvin, de acordo com Coelho \& Correa (2013), há a necessidade de implementação na Equação 2, proposta por Usgs (2015), subtraindo 273,15 de seu resultado, para a obtenção de imagem de temperatura em grau Celcius, assim:

$$
T s=\frac{K_{2}}{\ln \left(\frac{K_{1}}{L_{\lambda}}+1\right)}-273,15
$$

em que:

$T s=$ Temperatura de superfície, em grau Celcius $\left({ }^{\circ} \mathrm{C}\right)$
$K_{1}=$ Constante de calibração 1 (774.89)

$K_{2}=$ Constante de calibração 2 (1.321.08)

$L_{\lambda}=$ Radiância espectral em Watts $/\left(\mathrm{m}^{2 *} \mathrm{sr}^{*} \mu \mathrm{m}\right)$

\section{Identificação das áreas com Ilha de Calor Urbana (ICU)}

Após a importação das imagens processadas contendo a temperatura de superfície, e a imagem de alta resolução espacial, Pléiades, prosseguiu-se com a importação dos dados vetoriais: limites e vias de acesso na área urbana. Com base no limite da área urbana, foi criado um buffer de $200 \mathrm{~m}$, abrangendo a área rural no entorno do perímetro urbano, sendo esta a área de referência para a análise de ocorrência de ICU dentro da cidade de Ilha Solteira, conforme Figura 3.

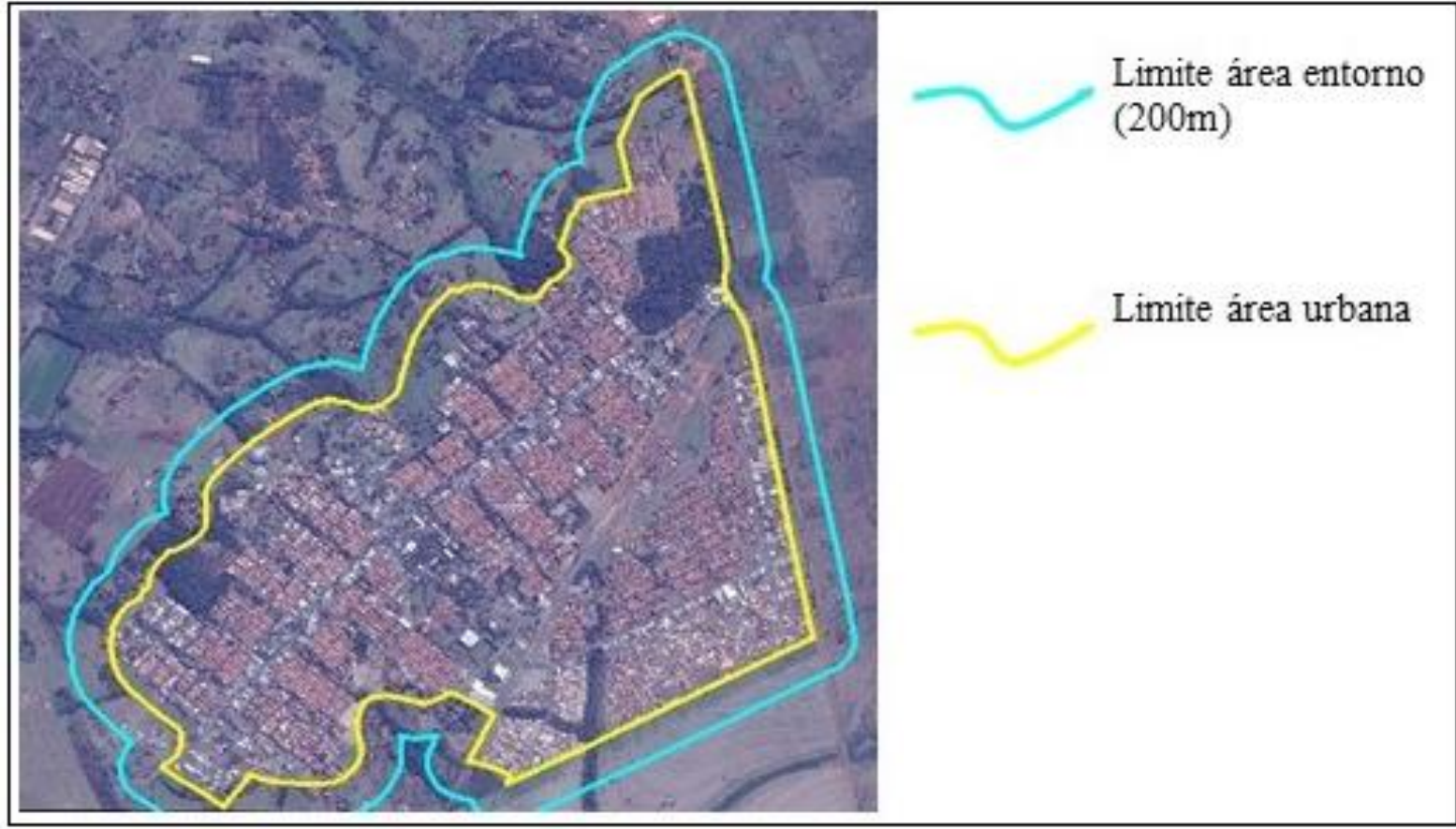

Figura 3 - Delimitação da área urbana e área de entorno.

Posteriormente, foi realizada a classificação dos valores das temperaturas, SIG Spring/INPE, definindo em classes com intervalo de $1^{\circ} \mathrm{C}$. A identificação dos polígonos contendo as ilhas de calor urbana (ICU) foi efetivada comparando-se a temperatura dos alvos presentes na área urbana, com os alvos presentes dentro do buffer de $200 \mathrm{~m}$. Estas ICU possuíam pelo menos $1{ }^{\circ} \mathrm{C}$ a mais do que alvos mais quentes dentro da área de entorno. Após a análise das 11 imagens, foram identificadas áreas com ocorrência de ICU em 2 datas, sendo estas, 07/02/2015 e 14/10/2015. As outras imagens foram identificadas áreas com temperatura mais elevada na área de entorno quando comparada com a área urbana.

\section{Vetorização das áreas com Ilha de Calor Urbana (ICU)}

Definidos os polígonos onde haviam a ocorrência da ICU, foi realizada a vetorização manual das classes de uso e ocupação do solo no interior das mesmas, sendo utilizada como referência a imagem de satélite de alta resolução (Pléiades).

Foram definidas 10 classes de uso e ocupação do solo, sendo estas: "Asfalto" (ASF), "Telhado cerâmico e asfalto" (TCA), "Telhado cerâmico e lajotas" (TCL), "Pavimentos cimentados" (PC), "Solo exposto" (SE), "Telhado amianto" (TA), "Telhado cerâmico" (TC), "Telhado de metal" (TM), "Vegetação arbórea" (VA) e "Vegetação 
herbácea" (VH).

As classes denominadas "Telhado cerâmico e asfalto" e "Telhado cerâmico e lajotas", identificam os passeios na área urbana onde a cobertura das residências apresentam telhado cerâmico e as vielas são pavimentadas com asfalto ou lajotas de cimento. Esses locais sofreram aglutinações em suas classes, pois, apesar da imagem Pléiades apresentar alta resolução espacial e radiométrica, não foi possível distinguir separadamente essas 02 classes de uso do solo em alguns passeios.

\section{Orientação de Vertentes}

Para a obtenção de informações relacionadas a orientações de vertentes, utilizou-se dados de altitude do sensor Aster/GDEM (Global Digital Elevation Models), resolução espacial de 30 metros. As classes foram definidas da seguinte forma: Norte "N" $\left(0-22,5^{\circ}\right)$; Nordeste "NE" $(22,5$ $\left.-67,5^{\circ}\right)$; Leste "E" $\left(67,5-112,5^{\circ}\right)$; Sudeste "SE" $\left(112,5-157,5^{\circ}\right)$; Sul "S" $\left(157,5-202,5^{\circ}\right)$; Sudoeste "SW" (202,5 - 247,5 $\left.5^{\circ} \mathrm{C}\right)$; Oeste "W" $\left(247,5-292,5^{\circ}\right)$; Noroeste "NW" $\left(292,5-337,5^{\circ}\right)$; Norte "N" $\left(337,5-360^{\circ}\right)$; PLANO $\left(-1-0^{\circ}\right)$.

\section{RESULTADOS E DISCUSSÃO}

\section{Ilha de Calor Urbana (ICU) em 07/02/2015}

De acordo com os dados de temperatura de superfície da imagem de 07/02/2015, foram constatadas a presença de 03 áreas ocorrendo o fenômeno ICU. Todas as áreas das ICU apresentaram uma temperatura variando entre 29 a $30^{\circ} \mathrm{C}$ (Figura 4). Dentro do buffer de $200 \mathrm{~m}$, foi verificada a presença de uma área com temperaturas entre 28 a $29^{\circ} \mathrm{C}$, identificada como área de referência para a determinação da ocorrência de ICU na área urbana. Esta área utilizada como referência apresentou as classes
Asfalto e Solo exposto.

A amplitude térmica das ICU foi de $1{ }^{\circ} \mathrm{C}$, sendo classificada como fraca magnitude, de acordo com a classificação de García (1996). A área total de ICU nesta data foi de 1,052ha, correspondendo a $0,15 \%$ da área urbana de Ilha Solteira.

De acordo com os dados obtidos pelo Canal CLIMA, a velocidade do vento em Ilha Solteira no momento da passagem do satélite, era de 1,4 $\mathrm{km} / \mathrm{h}$, considerada fraca, tal fato favoreceu a ocorrência de ICU na cidade.

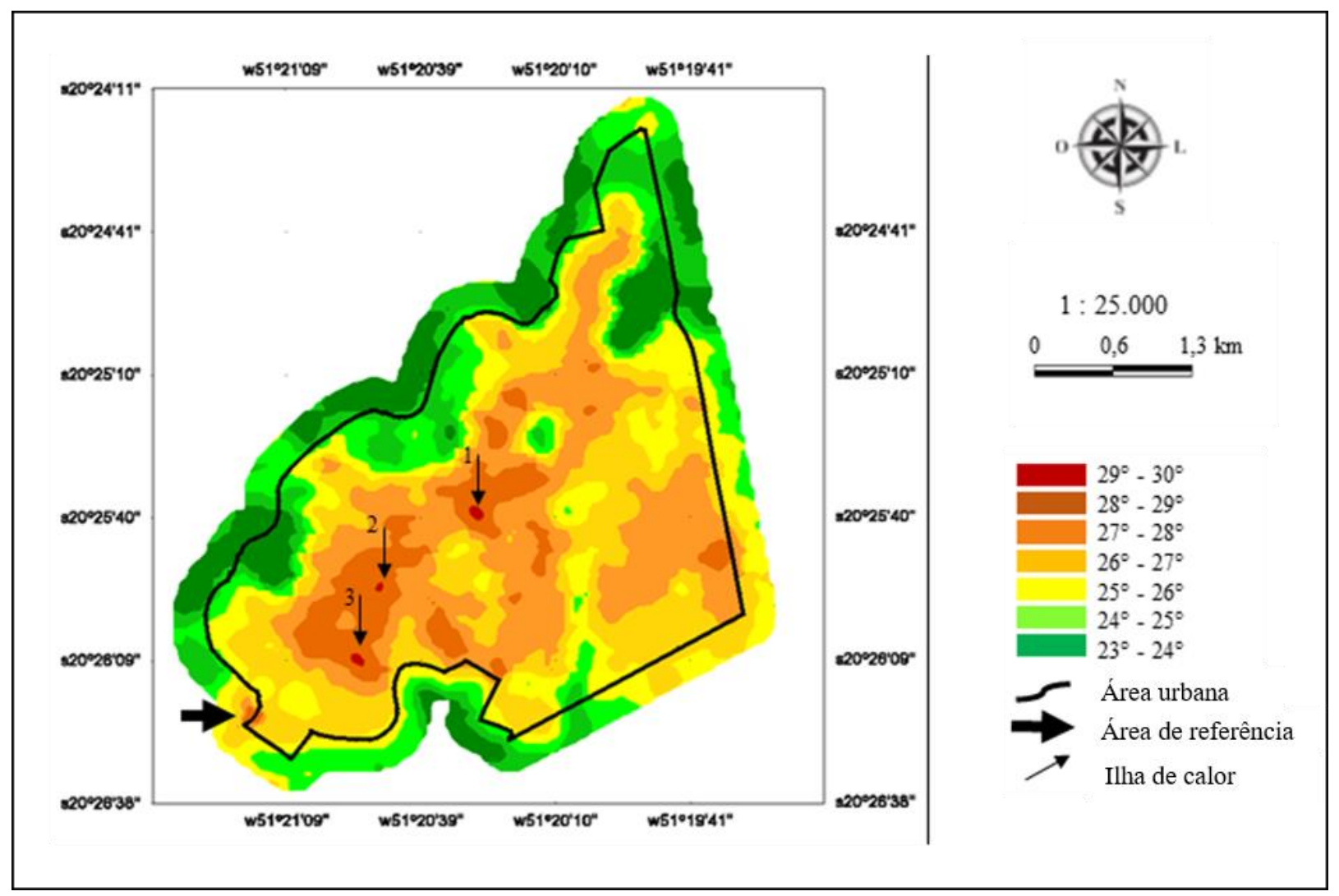

Figura 4 - Mapa de Ilhas de Calor Urbana em Ilha Solteira - SP, em 07/02/2015.

A Área 1 (Figura 5, Tabela 2), estava localizada no bairro Zona Sul de Ilha Solteira, em área residencial. Esta ICU possuía uma área de 0,175 ha, onde o uso do solo ficou restrito a classe TCA, ocupando uma área de $100 \%$ da área da ilha. A vertente SW ocupou uma área de 
0,036ha, correspondendo a 20,53\% da área total da ilha, onde, associada ao uso do solo, influenciou na temperatura local. Segundo Gartland (2010), materiais como concreto, amianto e asfalto, são reconhecidos pelas suas propriedades físicas de alteração do albedo natural da superfície, por serem bons absorvedores de calor, e consequentemente importantes emissores de radiação de ondas longas, o que explica a elevação das temperaturas.
De acordo com a Figura 6 e as Tabela 3, a ICU denominada Área 2, estava localizada no bairro Zona Norte, apresentando-se em área residencial. A área desta ICU foi de 0,434ha, onde identificou-se 03 classes de uso do solo, TCL $(64,25 \%)$, TCA $(23,15 \%)$ e ASF $(12,60 \%)$. A soma das vertentes de maior incidência solar na área urbana de Ilha Solteira, (SW e W), foi de $39,6 \%$.

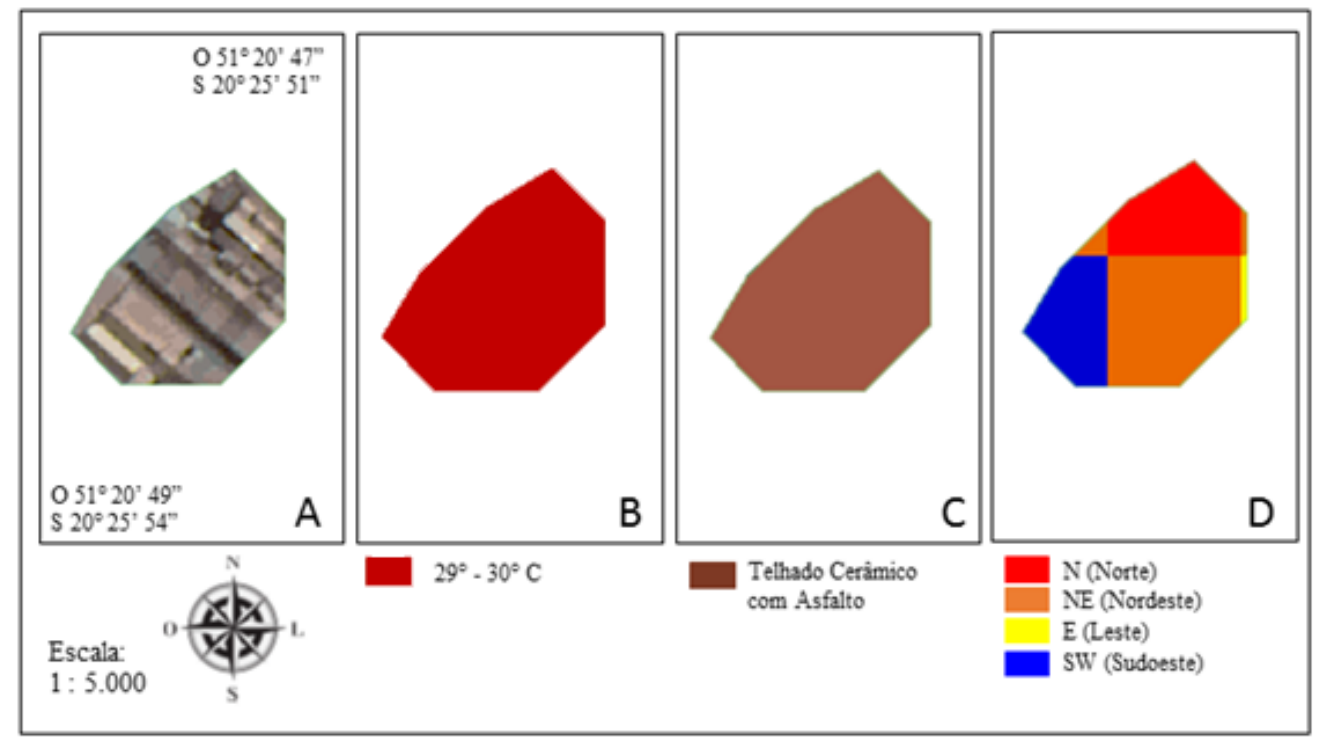

Figura 5 - Uso e Ocupação do solo e Orientação de Vertentes na Área 1. A - Imagem de satélite Pléiades; B - Temperatura de superfície da ICU; C - Classes de uso e ocupação do solo; D - Orientação de vertentes dentro da ICU.

Tabela 2 - Uso e ocupação do solo e orientação de vertentes na Área 1.

\begin{tabular}{c|c|c|c|c|c}
\hline \multirow{2}{*}{$29-\mathbf{3 0}^{\circ} \mathbf{C}$} & Uso e Ocupação do Solo (1) & \multicolumn{4}{|c}{ Orientacão de Vertentes ( $\left.{ }^{\mathbf{2}}\right)$} \\
\cline { 2 - 6 } & TCA & $\mathbf{N}$ & $\mathbf{N E}$ & $\mathbf{E}$ & $\mathbf{S W}$ \\
\hline Área (ha) & 0,175 & 0,050 & 0,086 & 0,003 & 0,036 \\
\hline Área (\%) & 100,00 & 28,70 & 49,00 & 1,77 & 20,53 \\
\hline
\end{tabular}

(1)TCA, Telhado cerâmico e asfalto $\left({ }^{2}\right)$ N, Norte; NE, Nordeste; E, Leste; SW, Sudoeste

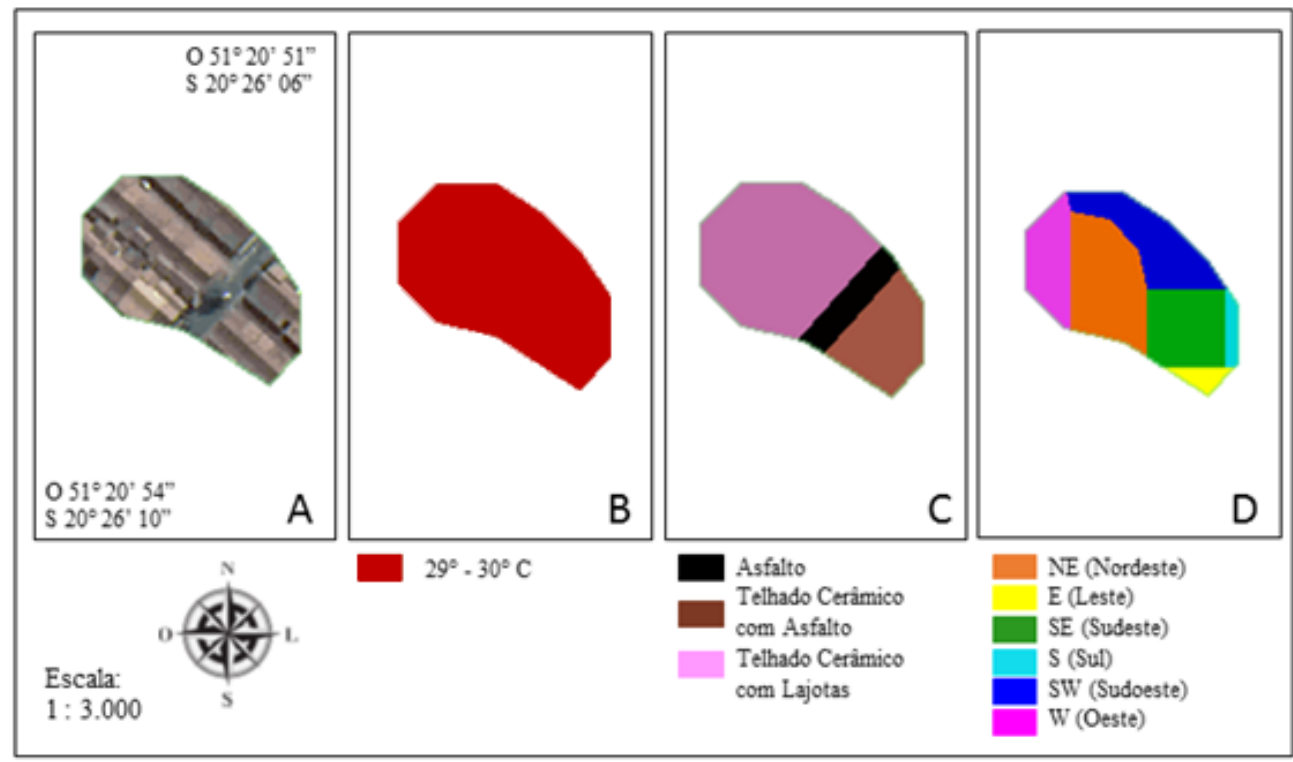

Figura 6 - Uso e Ocupação do solo e Orientação de Vertentes na Área 2. A - Imagem de satélite Pleiades; B - Temperatura de superfície da ICU; C - Classes de uso e ocupação do solo; D - Orientação de vertentes dentro da ICU. 
Tabela 3 - Uso e ocupação do solo e orientação de vertentes na Área 2.

\begin{tabular}{c|c|c|c|c|c|c|c|c|c}
\hline \multirow{2}{*}{$29-\mathbf{3 0}^{\circ} \mathbf{C}$} & \multicolumn{6}{|c|}{ Uso e Ocupação do Solo ( } & \multicolumn{6}{c}{ Orientação de Vertentes ( } \\
\cline { 2 - 10 } & ASF & TCA & TCL & NE & E & SE & S & SW & W \\
\hline Área (ha) & 0,055 & 0,101 & 0,279 & 0,138 & 0,018 & 0,095 & 0,011 & 0,099 & 0,073 \\
\hline Área (\%) & 12,60 & 23,15 & 64,25 & 31,67 & 4,19 & 21,95 & 2,58 & 22,90 & 16,70 \\
\hline
\end{tabular}

(1) ASF, Asfalto; TCA, Telhado cerâmico e asfalto; TCL, Telhado cerâmico e lajotas

$\left({ }^{2}\right)$ NE, Nordeste; E, Leste; SE, Sudeste; S, Sul; SW, Sudoeste; W, Oeste

A ICU denominada Área 3 (Figura 7, Tabela 4), estava localizada no bairro Zona Sul, em área residencial.

Esta ICU ocupou uma área de 0,441 ha, onde foram identificadas 3 classes de uso do solo, sendo estas, TCA $(78,57 \%)$, ASF $(14,51 \%)$ e TCL $(6,92 \%)$. As vertentes SW e W ocuparam $43,88 \%$ da área total da ICU, sendo assim, a orientação de vertentes favoreceu a ocorrência de ICU neste local.

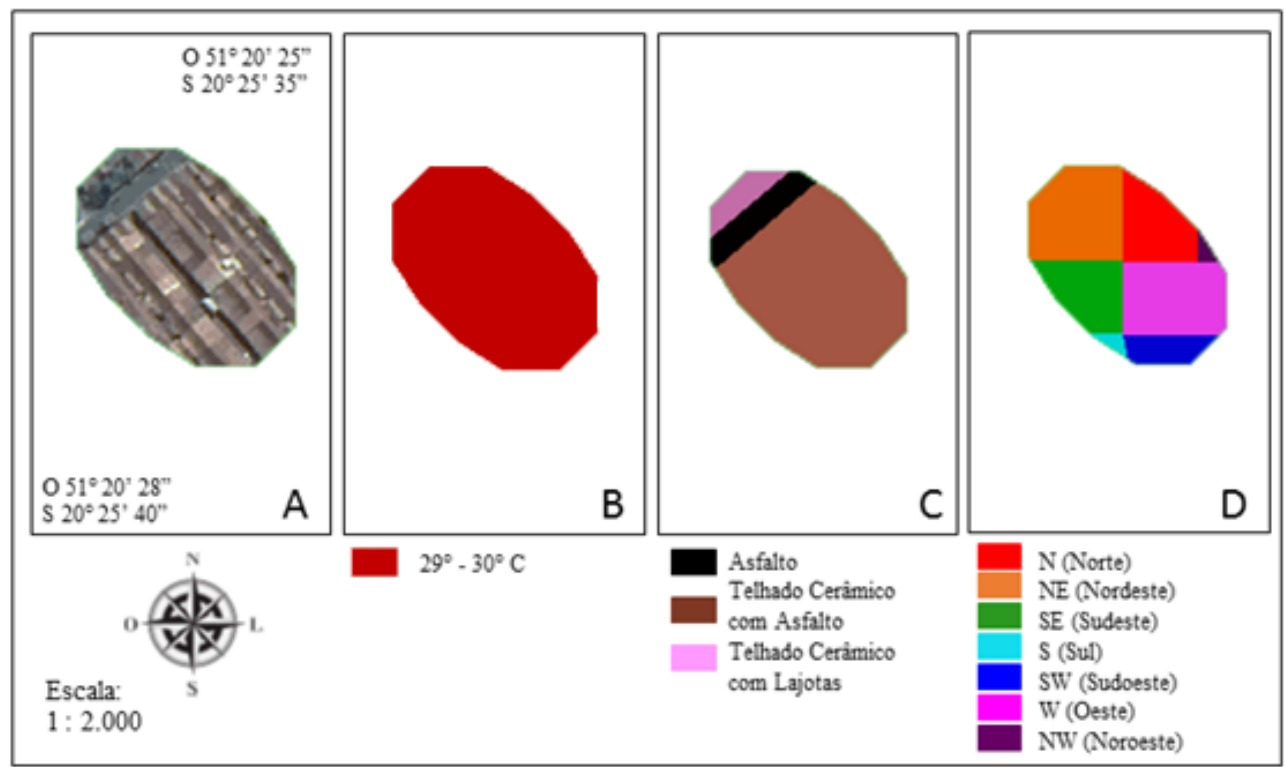

Figura 7 - Uso e Ocupação do solo e Orientação de Vertentes na Área 3. A - Imagem de satélite Pléiades; B - Temperatura de superfície da ICU; C - Classes de uso e ocupação do solo; D - Orientação de vertentes dentro da ICU.

Tabela 4 - Uso e ocupação do solo e orientação de vertentes na Área 3.

\begin{tabular}{c|c|c|c|c|c|c|c|c|c|c}
\hline \multirow{2}{*}{$29-\mathbf{3 0}^{\circ} \mathbf{C}$} & \multicolumn{6}{|c|}{ Uso e Ocupação do Solo (1) } & \multicolumn{7}{|c}{ Orientação de Vertentes $\left(^{\mathbf{2}}\right)$} \\
\cline { 2 - 11 } & ASF & TCA & TCL & N & NE & SE & S & SW & W & NW \\
\hline Área (ha) & 0,064 & 0,347 & 0,031 & 0,021 & 0,068 & 0,130 & 0,020 & 0,082 & 0,111 & 0,009 \\
\hline Área (\%) & 14,51 & 78,57 & 6,92 & 4,74 & 15,46 & 29,43 & 4,49 & 18,64 & 25,24 & 2,00 \\
\hline
\end{tabular}

(1) ASF, Asfalto; TCA, Telhado cerâmico e asfalto; TCL, Telhado cerâmico e lajotas

$\left({ }^{2}\right)$ N, Norte; NE, Nordeste; SE, Sudeste; S, Sul; SW, Sudoeste; W, Oeste; NW, Noroeste

\section{Ilha de Calor Urbana em 14/10/2015}

$\mathrm{Na}$ imagem de temperatura de superfície de 14/10/2015, foi possível identificar 8 áreas com ocorrência de ICU, denominadas Área 1, Área 2, Área 3, Área 4, Área 5, Área 6, Área 7 e Área 8. Todas áreas identificadas com ilha de calor estiveram na mesma faixa de temperatura, entre 33 e $34^{\circ} \mathrm{C}$ (Figura 8).

Dentro do buffer de $200 \mathrm{~m}$, foi encontrada uma área com temperatura entre 32 a $33^{\circ} \mathrm{C}$, identificada como área de referência para a determinação da ocorrência de ICU na área urbana.
Esta área utilizada como referência apresentou as classes Asfalto, Pavimentos cimentados e Vegetação Herbácea. A amplitude térmica das ICU foi de $1^{\circ} \mathrm{C}$, sendo classificada como fraca magnitude, de acordo com a classificação de García (1996). A área total de ICU foi de 15,261 ha, correspondendo a 2,21\% da área urbana de Ilha Solteira.

De acordo com os dados obtidos pelo Canal CLIMA, a velocidade do vento em Ilha Solteira no momento da passagem do satélite em $14 / 10 / 2015$, foi de $5,3 \mathrm{~km} / \mathrm{h}$, considerado fraco, tal fato favoreceu a ocorrência de ICU na cidade. 


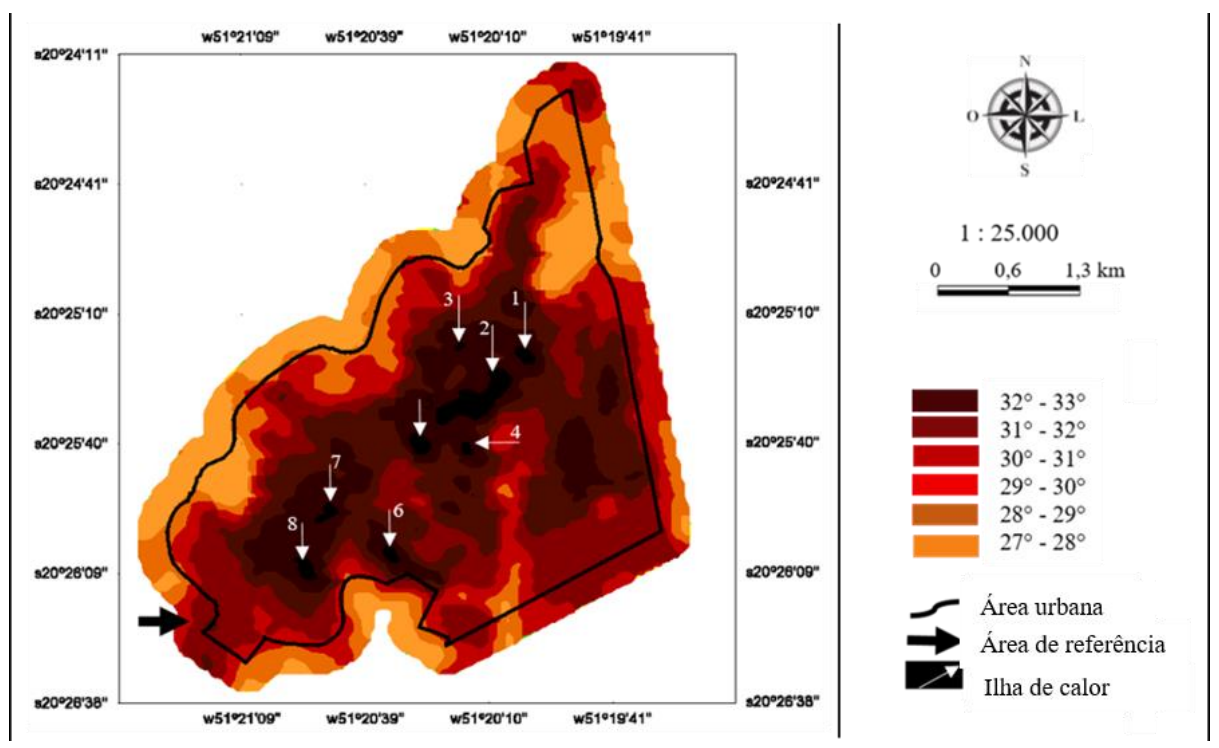

Figura 8 - Mapa de Ilhas de Calor Urbana em Ilha Solteira - SP, em 14/10/2015.

A ICU denominada Área 1 (Figura 9, Tabela 5), situada no bairro Zona Norte, estava sobre uma área residencial, ocupando uma área total de 1,143ha. Analisando esta ICU foi possível a identificação de 3 classes de uso do solo, TCL (74,90\%), TCA $(14,38 \%)$ e ASF $(10,72 \%)$.

A vertente de maior ocorrência foi a $\mathrm{SW}$, com
$65,07 \%$ da área total da ilha de calor, seguida da vertente $\mathrm{W}$, com $11,41 \%$. Desta forma, a orientação de vertentes influenciou na ocorrência de ICU, pois as vertentes de maior influência na temperatura de superfície em Ilha Solteira, representaram $76,48 \%$ da área total da ilha de calor.

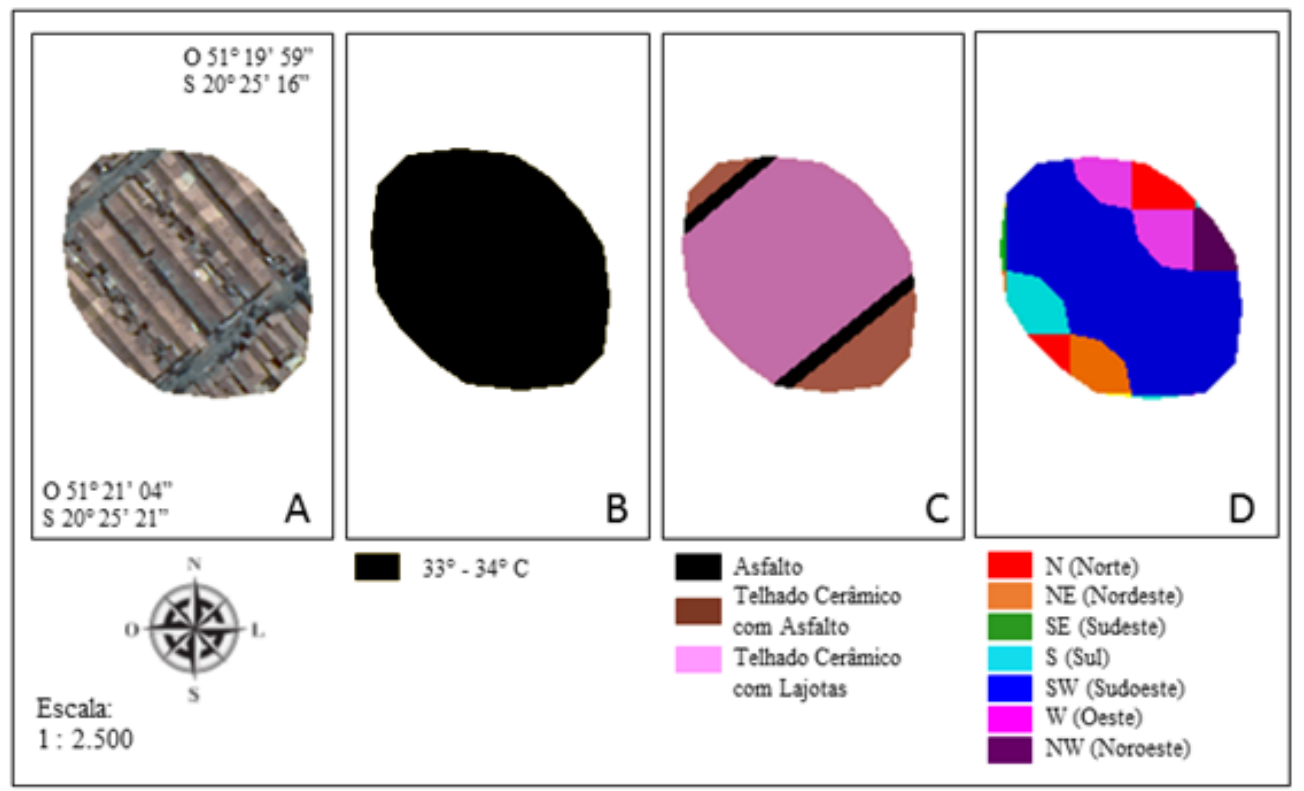

Figura 9 - Uso e Ocupação do solo e Orientação de Vertentes na Área 1. A - Imagem de satélite Pléiades; B - Temperatura de superfície da ICU; C - Classes de uso e ocupação do solo; D - Orientação de vertentes dentro da ICU.

Tabela 5 - Uso e ocupação do solo e orientação de vertentes na Área 1.

\begin{tabular}{|c|c|c|c|c|c|c|c|c|c|c|c|}
\hline \multirow{2}{*}{$33-34^{\circ} \mathrm{C}$} & \multicolumn{3}{|c|}{ Uso e Ocupação do Solo (1) } & \multicolumn{8}{|c|}{ Orientação de Vertentes $\left({ }^{2}\right)$} \\
\hline & ASF & TCA & TCL & $\mathbf{N}$ & NE & $\mathbf{E}$ & SE & $\mathbf{S}$ & SW & $\mathbf{W}$ & NW \\
\hline Área (ha) & 0,123 & 0,164 & 0,856 & 0,073 & 0,069 & 0,001 & 0,008 & 0,071 & 0,744 & 0,130 & 0,046 \\
\hline Área (\%) & 10,72 & 14,38 & 74,90 & 6,39 & 6,07 & 0,08 & 0,73 & 6,24 & 65,07 & 11,41 & 4,03 \\
\hline
\end{tabular}

(1) ASF, Asfalto; TCA, Telhado cerâmico e asfalto; TCL, Telhado cerâmico e lajotas

$\left(^{2}\right)$ N, Norte; NE, Nordeste; E, Leste; SE, Sudeste; S, Sul; SW, Sudoeste; W, Oeste; NW, Noroeste

A Área 2 (Figura 10, Tabela 6 e 7) estava área comercial. A ICU denominada Área 2, localizada no Bairro Zona Norte, abrangendo em ocupou uma área de 8,371ha. Foi possível sua maior parte área residencial, e em minoria, constatar a ocorrência de 07 classes de uso do 
solo. As classes destinadas a área residencial, TCA e TCL, ocuparam um espaço de 7,016ha, equivalente a $83,81 \%$ da área total da ICU.

A Área 3 (Figura 11, Tabela 8), localizada no bairro Zona Norte, ocupou um espaço de 0,247 ha em área residencial. A classe de uso do solo encontrada nesta ICU foi apenas a TCA, ocupando toda a área da ilha de calor. A vertente sudoeste (W) ocupou apenas $1,87 \%$ da área total, desta forma, não havendo muita incidência solar direta nesta área, atribuindo a classe de uso do solo, o motivo da alta temperatura local.

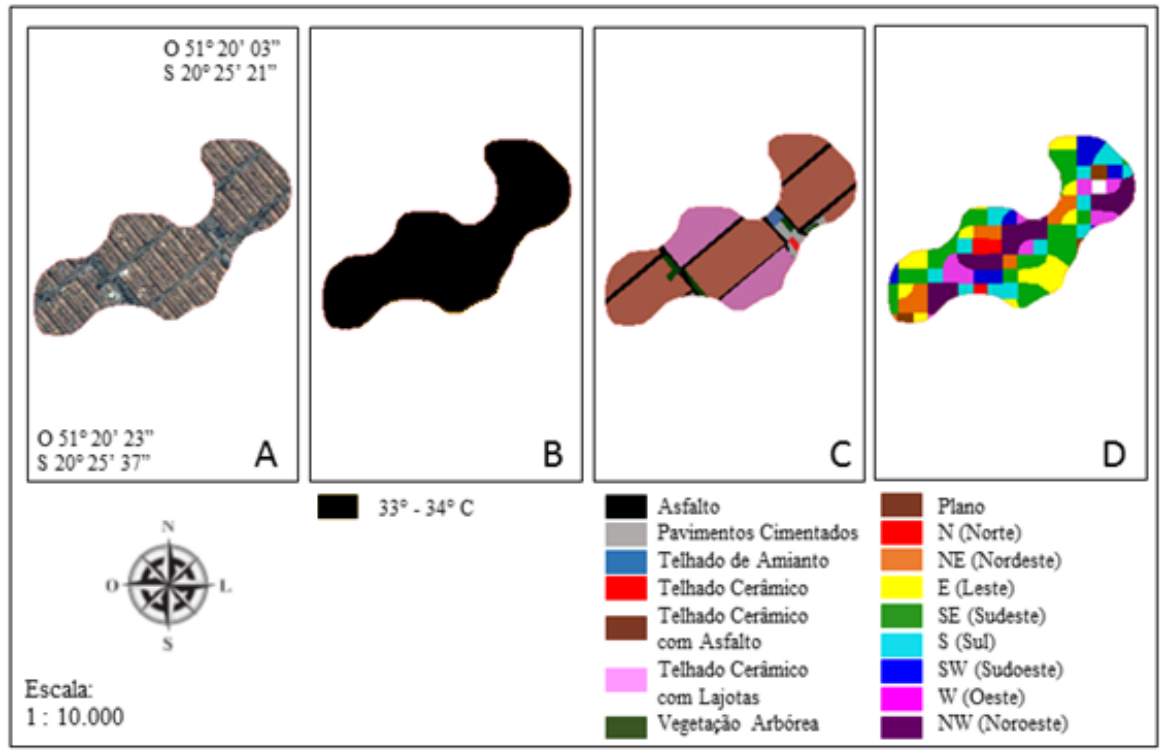

Figura 10. Uso e Ocupação do solo e Orientação de Vertentes na Área 2. A - Imagem de satélite Pleiades; B Temperatura de superfície da ICU; C - Classes de uso e ocupação do solo; D - Orientação de vertentes dentro da ICU.

Tabela 6 - Uso e ocupação do solo na Área 2.

\begin{tabular}{c|c|c|c|c|c|c}
\hline \multirow{2}{*}{$33-\mathbf{3 4}^{\circ} \mathbf{C}$} & \multicolumn{5}{|c}{ Uso e Ocupação do Solo (1) } \\
\cline { 2 - 7 } & ASF & TCA & TCL & PC & TA & TC \\
\hline Área (ha) & 1,087 & 5,285 & 1,731 & 0,171 & 0,069 & 0,029 \\
\hline Área (\%) & 12,99 & 63,13 & 20,67 & 2,04 & 0,82 & 0,35 \\
\hline
\end{tabular}

(1) ASF, Asfalto; TCA, Telhado cerâmico e asfalto; TCL, Telhado cerâmico e lajotas; PC Pavimentos cimentados; TA, Telhado amianto; TC, Telhado cerâmico; TM, Telhado de metal.

Tabela 7 - Orientação de Vertentes na Área 2

\begin{tabular}{c|c|c|c|c|c|c|c|c|c}
\hline \multirow{2}{*}{$33-\mathbf{3 4}^{\circ} \mathbf{C}$} & \multicolumn{8}{|c}{ Orientação de Vertentes (1) } \\
\cline { 2 - 10 } & $\mathbf{N}$ & $\mathbf{N E}$ & $\mathbf{E}$ & $\mathbf{S E}$ & $\mathbf{S}$ & $\mathbf{S W}$ & $\mathbf{W}$ & $\mathbf{N W}$ & PLANO \\
\hline Área (ha) & 0,261 & 0,829 & 1,169 & 2,012 & 1,169 & 0,675 & 0,697 & 1,396 & 0,164 \\
\hline Área (\%) & 3,12 & 9,90 & 13,96 & 24,04 & 13,96 & 8,06 & 8,32 & 16,68 & 1,95 \\
\hline
\end{tabular}

(1) N, Norte; NE, Nordeste; E, Leste; SE, Sudeste; S, Sul; SW, Sudoeste; W, Oeste; NW, Noroeste

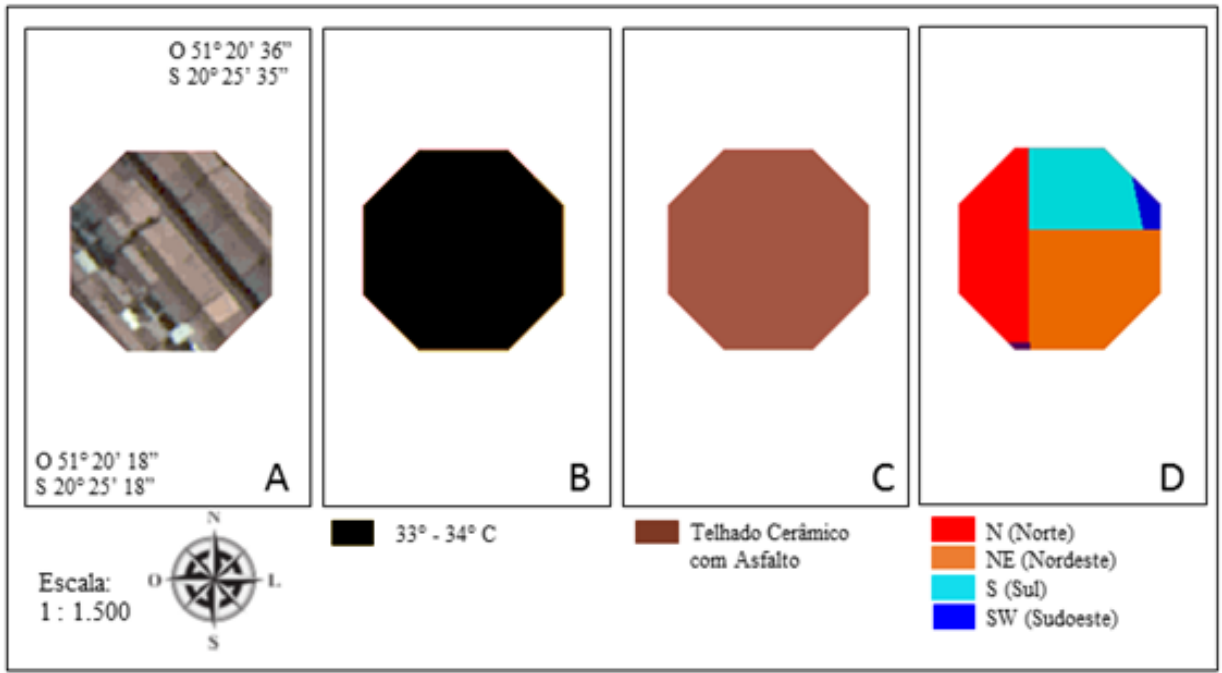

Figura 11 - Uso e Ocupação do solo e Orientação de Vertentes na Área 3. A - Imagem de satélite Pleiades; B Temperatura de superfície da ICU; C - Classes de uso e ocupação do solo; D - Orientação de vertentes dentro da ICU. 
Tabela 8 - Uso e ocupação do solo e orientação de vertentes na Área 3

\begin{tabular}{c|c|c|c|c|c|c}
\hline \multirow{2}{*}{$33-\mathbf{3 4}^{\circ} \mathbf{C}$} & Uso e Ocupação do Solo (1) & \multicolumn{5}{|c}{ Orientação de Vertentes ( } \\
\cline { 2 - 7 } & TCA & N & NE & S & SW & NW \\
\hline Área (ha) & 0,247 & 0,078 & 0,105 & 0,058 & 0,005 & 0,001 \\
\hline Área (\%) & 100,00 & 31,51 & 42,58 & 23,68 & 1,87 & 0,36 \\
\hline
\end{tabular}

(1)TCA, Telhado cerâmico e asfalto $\left(^{2}\right)$ N, Norte; NE, Nordeste; S, Sul; SW, Sudoeste; NW, Noroeste

A Área 4 (Figura 12, Tabela 9), localizada no bairro Zona Norte, em área residencial, ocupa uma área de 0,522ha.

Foram identificadas 3 classes de uso do solo
TCL $(73,23 \%)$, TCA $(15,20 \%)$ e ASF $(11,56 \%)$. Quanto a orientação de vertentes, a vertente de maior ocorrência foi a W, ocupando uma 'área de $48,25 \%$ da área total.

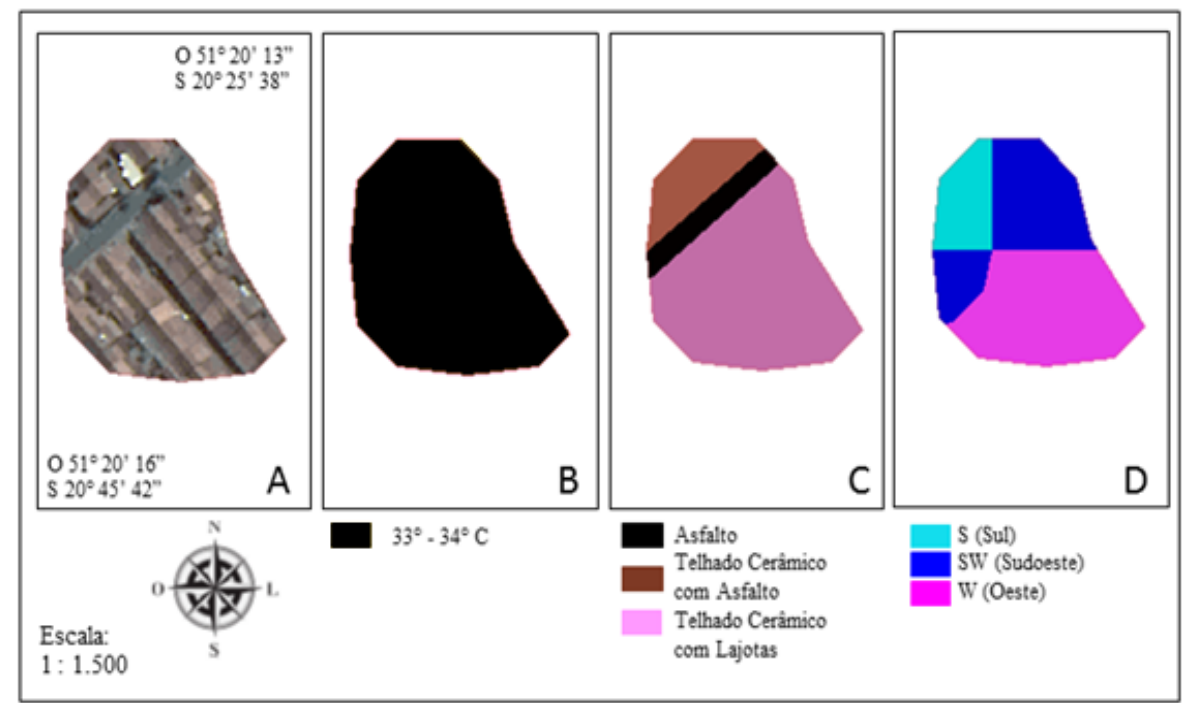

Figura 12 - Uso e Ocupação do solo e Orientação de Vertentes na Área 4. A - Imagem de satélite Pleiádes; B Temperatura de superfície da ICU; C - Classes de uso e ocupação do solo; D - Orientação de vertentes dentro da ICU.

Tabela 9 - Uso e ocupação do solo e orientação de vertentes na Área 4.

\begin{tabular}{c|c|c|c|c|c|c}
\hline \multirow{2}{*}{$33-\mathbf{3 4}^{\circ} \mathbf{C}$} & \multicolumn{3}{|c|}{ Uso e Ocupação do Solo (1) } & \multicolumn{3}{|c}{ Orientação de Vertentes ( ${ }^{\mathbf{2}}$ ) } \\
\cline { 2 - 7 } & $\mathbf{A S F}$ & TCA & TCL & S & SW & W \\
\hline Área (ha) & 0,060 & 0,079 & 0,383 & 0,082 & 0,189 & 0,252 \\
\hline Área (\%) & 11,56 & 15,20 & 73,23 & 15,62 & 36,13 & 48,25 \\
\hline
\end{tabular}

(1) ASF, Asfalto; TCA, Telhado cerâmico e asfalto; TCL, Telhado cerâmico e lajotas

( $\left.{ }^{2}\right)$ S, Sul; SW, Sudoeste; W, Oeste

A Área 5 (Figura 13, Tabela 10), foi identificada no bairro Zona Norte de Ilha Solteira, ocupando uma área totalde 1,592ha. Sua ocorrência foi em área residencial, onde identificou-se as classes TCA (86,35\%), ASF $(11,19 \%)$ e TCL $(2,46 \%)$. As vertentes W e SW, ocuparam uma área de 0,514ha, equivalente a $32,28 \%$ da área total desta ICU.

A ICU denominada Área 6 (Figura 14, Tabela 11), estava localizada no bairro Zona Sul, ocupada por área residencial. A área total desta ICU foi de $0,882 \mathrm{ha}$, onde foram identificadas as seguintes classes: TCA $(54,99 \%)$, TCL $(36,04 \%)$ e $\operatorname{ASF}(8,97 \%)$.

A vertente NW apresentou uma área referente a $57.73 \%$ da área total da ICU.

A área 7 (figura 15, Tabela 12 e 13) localizada no bairro Zona Sul, abrangendo áreas residenciais em sua maioria, e comerciais. A área total desta ICU foi de 0,982ha. Foi possível constatar a ocorrência das seguintes classes: TCA $(75,97 \%)$, ASF $(9,75 \%)$, TA $(4,05 \%), \mathrm{VH}$ $(3,59 \%)$, PC $(3,28 \%)$, VA $(2,54 \%)$ e TCL $(0,81 \%)$.

A ICU denominada Área 8 (Figura 16, Tabela 14), estava localizada no bairro Zona Sul, em área residencial. A área total desta ICU foi de 1,521 ha, onde pode ser constatado a presença de 3 classes de uso do solo, TCL $(68,30 \%)$, TCA $(17,62 \%)$ e ASF $(14,08 \%)$. Esta ilha foi localizada em área residencial.

A vertente de maior ocorrência na área foi SE, com $38,45 \%$ da área total, seguida por $\mathrm{W}$, com $15,08 \%$, salientando que estas são as vertentes que mais influenciam na formação de ilhas de calor, pois tem maior exposição à radiação solar. 


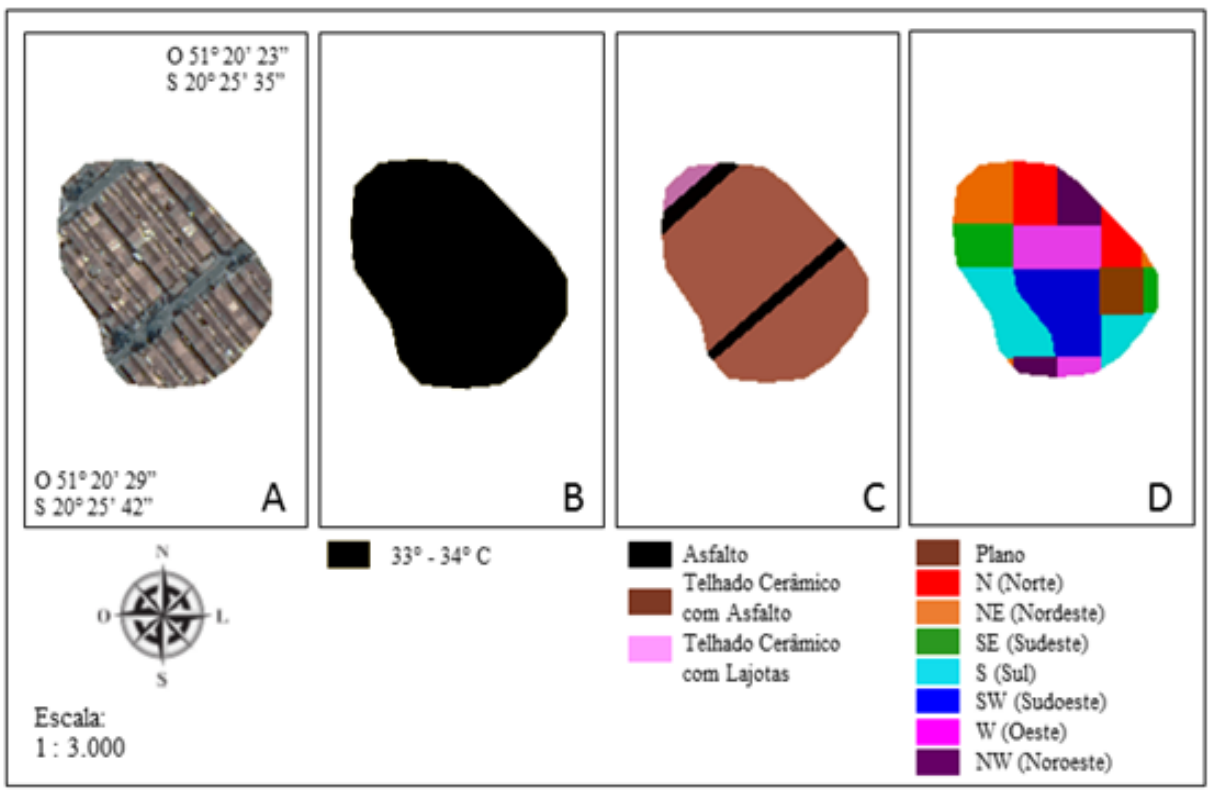

Figura 13 - Uso e Ocupação do solo e Orientação de Vertentes na Área 5. A - Imagem de satélite Pleiades; B Temperatura de superfície da ICU; C - Classes de uso e ocupação do solo; D - Orientação de vertentes dentro da ICU.

Tabela 10 - Uso e ocupação do solo e orientação de vertentes na Área 5.

\begin{tabular}{c|c|c|c|c|c|c|c|c|c|c|c}
\hline \multirow{2}{*}{$33-\mathbf{3 4}^{\circ} \mathbf{C}$} & \multicolumn{4}{|c|}{ Uso e Ocupação do Solo (1) } & \multicolumn{1}{c}{ Orientação de Vertentes $\mathbf{( 2}^{\mathbf{2}}$} \\
\cline { 2 - 12 } & $\mathbf{A S F}$ & TCA & TCL & N & NE & SE & S & SW & W & NW & PLANO \\
\hline Área (ha) & 0,178 & 1,375 & 0,039 & 0,222 & 0,171 & 0,160 & 0,307 & 0,285 & 0,229 & 0,122 & 0,096 \\
\hline Área (\%) & 11,19 & 86,35 & 2,46 & 13,94 & 10,72 & 10,07 & 19,26 & 17,87 & 14,41 & 7,68 & 6,04 \\
\hline
\end{tabular}

(1) ASF, Asfalto; TCA, Telhado cerâmico e asfalto; TCL, Telhado cerâmico e lajotas

$\left({ }^{2}\right)$ N, Norte; NE, Nordeste; E, Leste; SE, Sudeste; S, Sul; SW, Sudoeste; W, Oeste; NW, Noroeste

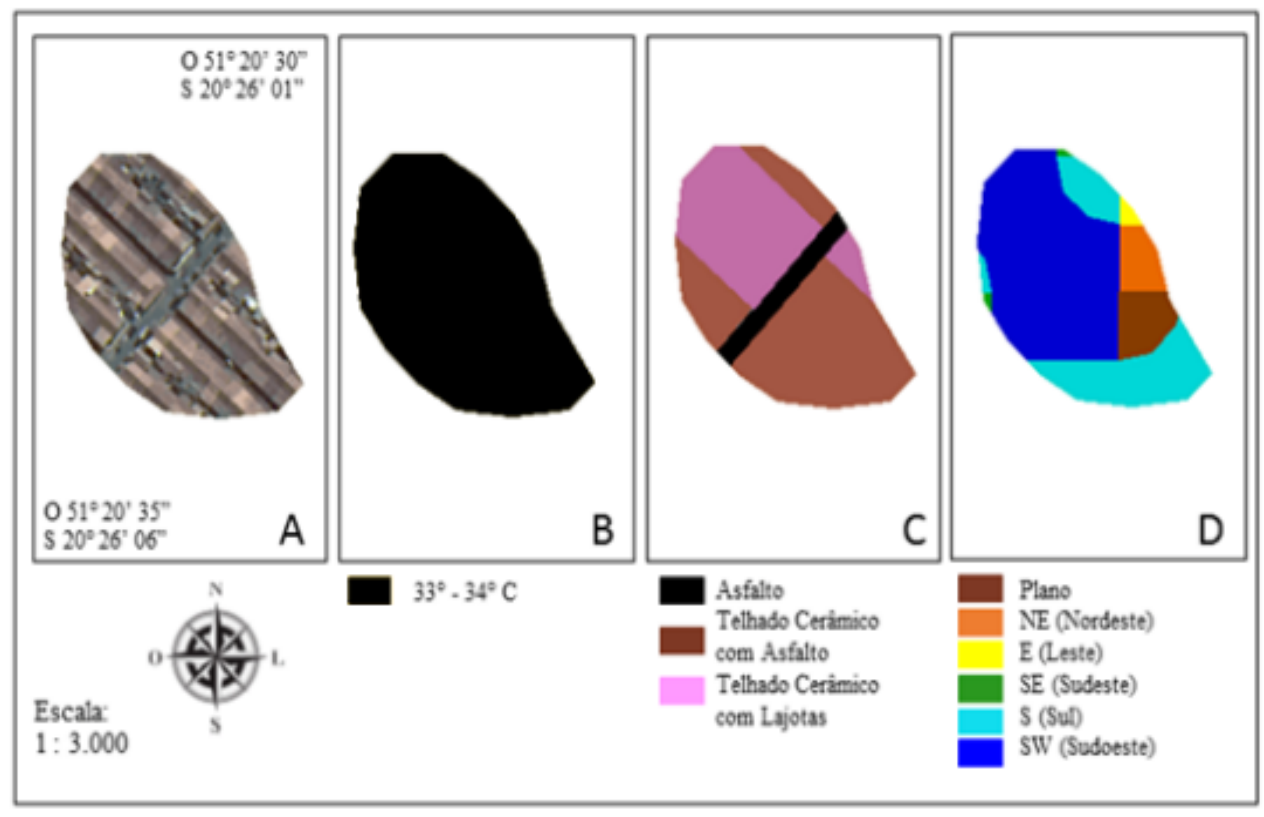

Figura 14 - Uso e Ocupação do solo e Orientação de Vertentes na Área 6. A - Imagem de satélite Pleiades; B Temperatura de superfície da ICU; C - Classes de uso e ocupação do solo; D - Orientação de vertentes dentro da ICU.

Tabela 11 - Uso e ocupação do solo e orientação de vertentes na Área 6.

\begin{tabular}{c|c|c|c|c|c|c|c|c|c}
\hline \multirow{2}{*}{$33-\mathbf{3 4}^{\circ} \mathbf{C}$} & \multicolumn{6}{|c|}{ Uso e Ocupação do Solo (1) } & \multicolumn{5}{c}{ Orientação de Vertentes ( } \\
\cline { 2 - 9 } & ASF & TCA & TCL & NE & E & SE & S & SW & PLANO \\
\hline Área (ha) & 0,079 & 0,485 & 0,318 & 0,059 & 0,008 & 0,004 & 0,232 & 0,509 & 0,070 \\
\hline Área (\%) & 8,97 & 54,99 & 36,04 & 6,63 & 0,95 & 0,50 & 26,25 & 57,72 & 7,95 \\
\hline
\end{tabular}

(1) ASF, Asfalto; TCA, Telhado cerâmico e asfalto; TCL, Telhado cerâmico e lajotas

$\left(^{2}\right)$ N, Norte; E, Leste; SE, Sudeste; S, Sul; SW, Sudoeste 


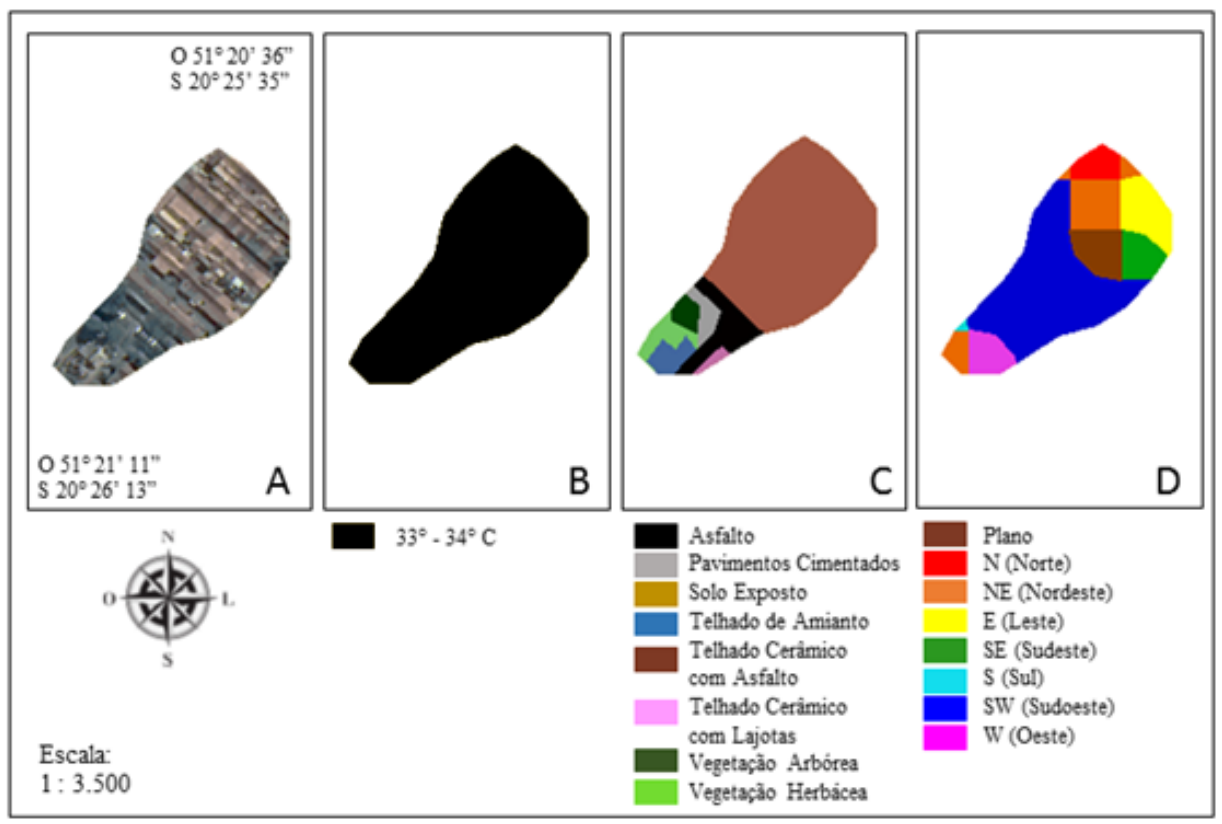

Figura 15 - Uso e Ocupação do solo e Orientação de Vertentes na Área 7. A - Imagem de satélite Pleiades; B Temperatura de superfície da ICU; C - Classes de uso e ocupação do solo; D - Orientação de vertentes dentro da ICU.

Tabela 12 - Uso e ocupação do solo na Área 7.

\begin{tabular}{c|c|c|c|c|c|c|c|c}
\hline \multirow{2}{*}{$33-\mathbf{~ 3 4}^{\circ} \mathbf{C}$} & \multicolumn{6}{|c|}{ Uso e Ocupação do Solo (1) } & \multirow{2}{*}{ TOTAL } \\
\cline { 2 - 9 } & ASF & TCA & TCL & PC & TA & VA & VH & \\
\hline Área (ha) & 0,096 & 0,746 & 0,008 & 0,032 & 0,040 & 0,025 & 0,035 & 0,982 \\
\hline Área (\%) & 9,75 & 75,97 & 0,81 & 3,28 & 4,05 & 2,54 & 3,59 & 100,00 \\
\hline
\end{tabular}

(1) ASF, Asfalto; TCA, Telhado cerâmico e asfalto; TCL, Telhado cerâmico e lajotas; TA, Telhado amianto; VA, Vegetação arbórea; VH, Vegetação herbácea

Tabela 13 - 1Orientação de Vertentes o na Área 7.

\begin{tabular}{c|c|c|c|c|c|c|c|c|c}
\hline \multirow{2}{*}{$33-\mathbf{3 4}^{\circ} \mathbf{C}$} & \multicolumn{7}{|c}{ Orientação de Vertentes (1) } & \multirow{2}{*}{ TOTAL } \\
\cline { 2 - 10 } & $\mathbf{N}$ & $\mathbf{N E}$ & $\mathbf{E}$ & $\mathbf{S E}$ & $\mathbf{S}$ & $\mathbf{S W}$ & $\mathbf{W}$ & PLANO & \\
\hline Área (ha) & 0,053 & 0,141 & 0,104 & 0,068 & 0,003 & 0,483 & 0,057 & 0,075 & 0,982 \\
\hline Área (\%) & 5,35 & 14,37 & 10,54 & 6,89 & 0,26 & 49,19 & 5,76 & 7,65 & 100,00 \\
\hline
\end{tabular}

(1) N, Norte; NE, Nordeste; E, Leste; SE, Sudeste; S, Sul; SW, Sudoeste; W, Oeste; NW, Noroeste

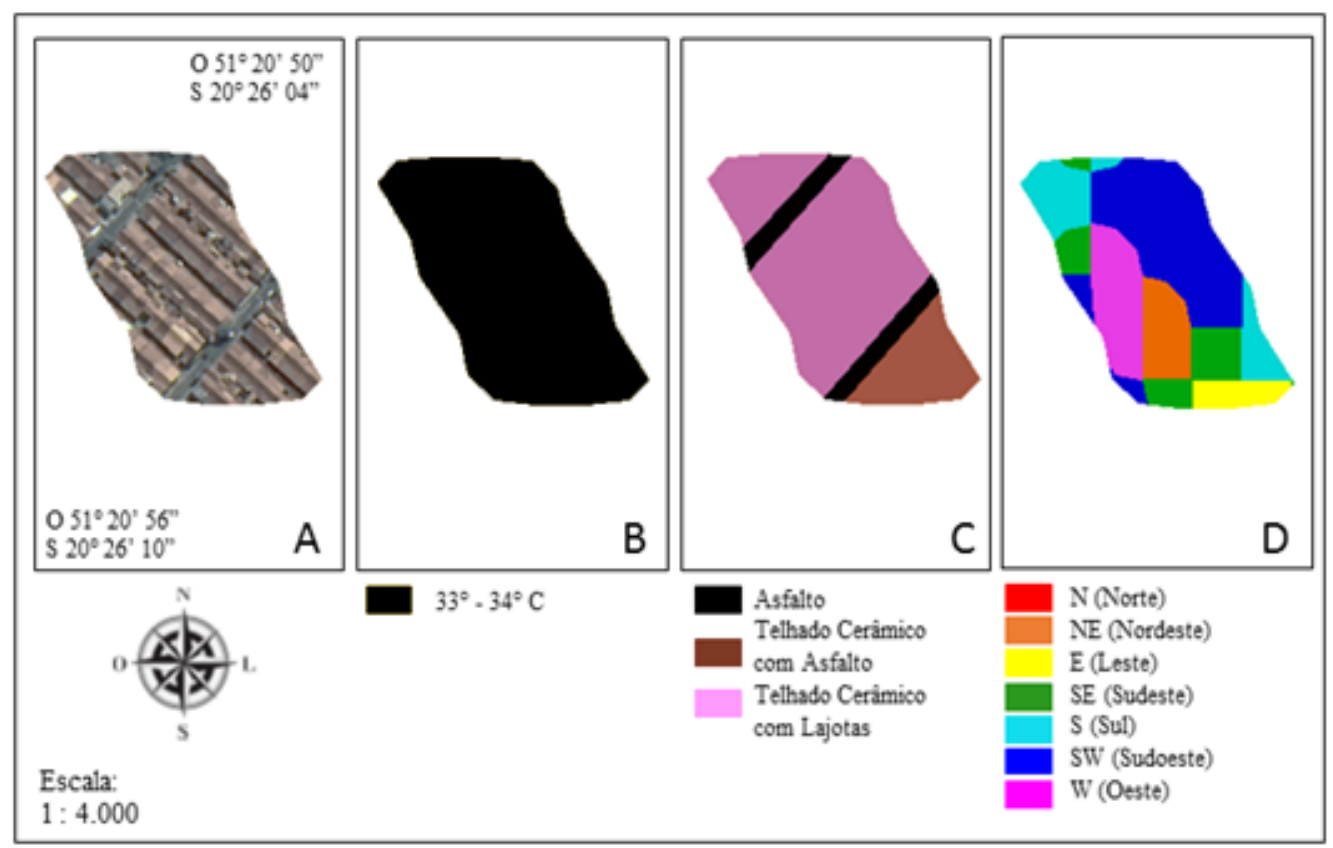

Figura 16 - Uso e Ocupação do solo e Orientação de Vertentes na Área 8. A - Imagem de satélite Pleiades; B Temperatura de superfície da ICU; C - Classes de uso e ocupação do solo; D - Orientação de vertentes dentro da ICU 
Tabela 14 - Uso e ocupação do solo e orientação de vertentes na Área 8.

\begin{tabular}{c|c|c|c|c|c|c|c|c|c}
\hline \multirow{2}{*}{$33-\mathbf{3 4}^{\circ} \mathbf{C}$} & \multicolumn{2}{|c|}{ Uso e Ocupação do Solo ( } & \multicolumn{6}{c}{ Orientação de Vertentes $\mathbf{(}^{2}$ ) } \\
\cline { 2 - 10 } & ASF & TCA & TCL & NE & E & SE & S & SW & W \\
\hline Área (ha) & 0,214 & 0,268 & 1,039 & 0,169 & 0,097 & 0,213 & 0,228 & 0,585 & 0,229 \\
\hline Área (\%) & 14,08 & 17,62 & 68,30 & 11,09 & 6,36 & 14,00 & 15,00 & 38,45 & 15,08 \\
\hline
\end{tabular}

(1) ASF, Asfalto; TCA, Telhado cerâmico e asfalto; TCL, Telhado cerâmico e lajotas

$\left({ }^{2}\right)$ NE, Nordeste; E, Leste; SE, Sudeste; S, Sul; SW, Sudoeste; W, Oeste

De acordo com as 8 datas analisadas, pode-se constatar que as amplitudes térmicas das ilhas de calor, em sua maioria foram de $1^{\circ} \mathrm{C}$, exceto em $02 / 04 / 2014$, onde a amplitude térmica foi de $2^{\circ} \mathrm{C}$ e 17/03/2014, amplitude térmica de $3^{\circ} \mathrm{C}$.

As classes de maior ocorrência em ICU encontradas foram: TCA, Telhado cerâmico e asfalto; TCL, Telhado cerâmico e lajotas; ASF, asfalto, e as menores são as classes de vegetação. Estes dados estão de acordo com Coltri et al. (2007), onde afirma que a morfologia das ilhas de calor é, em sua maioria, sempre a mesma: cimento, telhas de cimento e amianto, asfalto.

A intensidade das ilhas de calor está intimamente relacionada com a quantidade de área verde, sendo assim, todas as ICU são caracterizadas pelo excesso de material de construção civil e pouca ou nenhuma área verde.

As ilhas de calor se repetem em várias datas analisadas, principalmente no bairro Zona Norte. As áreas de repetição estão sempre associadas ao telhado cerâmico, pavimento asfáltico e pavimentos de concreto.

Alguns núcleos se repetem no bairro Zona Sul, a ocorrência está associada à disposição adensadas de casas, impedindo a circulação do vento, e ao pavimento empregado nas vielas.

Em áreas comerciais a temperatura de superfície é mais alta onde há pavimentação asfáltica (bolsões de estacionamento), telhado de amianto e telhado de metal.

$\mathrm{O}$ material de pavimentação de maior ocorrência em todas as ilhas de calor constatadas, foi o pavimento asfáltico, em seguida, lajotas de concreto.

Tal afirmação corrobora com Saydelles (2005), onde afirma a formação do fenômeno das ilhas de calor urbana está relacionada com as atividades desempenhadas pelos seres humanos e com a intensidade dos materiais empregados na expansão das malhas urbanas, (concreto, asfalto, telhados) os quais absorvem e conservam o calor proveniente da radiação solar, sendo assim, alimentando positivamente o aumento da temperatura local.

Em algumas ilhas de calor foi observado a presença da classe VA (vegetação arbórea) e VH (vegetação herbácea). As espécies arbóreas que ocorre nas áreas residenciais, com o intuito paisagístico e arrefecimento da temperatura ambiente, não foram suficientes para mitigar o efeito calorífico, devido a descontinuidade no número de indivíduos.

Situação diferente foi observada nas áreas com vegetação arbórea, em maior quantidade, como o Parque da Mantiqueira e o Zoológico, onde apresentaram as temperaturas mais amenas em todas as datas, concordando com Ferreira et al. (2015), onde áreas verdes promovem ilhas de frescor, e minimizam os efeitos extremos da radiação solar.

As vegetações herbáceas encontradas nas ilhas de calor, ao longo da cidade, estão em estágio de degradação, dessa forma, a vegetação apresenta características de emissividade semelhantes a solo exposto, possuindo alta amplitude térmica, e aquece rapidamente durante o período de exposição solar, conforme afirma Gartland (2010).

Outros fatores interferem na ocorrência de ICU, como fatores climatológicos, (velocidade do vento, temperatura do ar e precipitação) e também a orientação das vertentes.

A vertente exposta diretamente a incidência solar, associada ao material empregado na área, pode aumentar o armazenamento de calor em seu volume, havendo o acumulo de energia, promovendo a radiação de ondas longas, aumentando a temperatura de superfície.

Em áreas com maior exposição à radiação solar o ideal é aplicação de projetos paisagísticos, procurando promover sombras nestes locais, concordando com Fialho (2012), onde vertentes mais sombreadas durante o dia se esfriam rapidamente em relação aquelas que receberam maior quantidade de luz solar.

\section{CONSIDERAÇÕES FINAIS}

Em todas as datas analisadas, as classes de uso do solo que mais contribuíram para a formação

das ICU, foram TCA (telhado cerâmico e asfalto), TCL (telhado cerâmico e lajotas) e ASF 
(asfalto). Na cidade de Ilha Solteira, várias ilhas de calor se repetiram em diferentes datas analisadas, na maioria das vezes havendo mudanças em relação a sua extensão.

As áreas de maior ocorrência de ICU estão instaladas construções residenciais, com cobertura de telhado cerâmico, este efeito ocorre devido o padrão arquitetônico compacto entre as residências, dificultando a circulação do ar, principalmente no bairro Zona Norte, pois, em todas as datas analisadas foram encontradas ICU.

Os resultados mostraram que o aumento da temperatura de superfície está relacionado ao uso e ocupação do solo, associados a fatores climatológicos e a orientação de vertentes. Áreas com pouca vegetação arbórea influenciam diretamente no aumento da temperatura de superfície local, tal fato é de grande interesse a recomposição paisagística de determinadas áreas, aumentando a vegetação, pois atuam diretamente na redução das temperaturas, pela evapotranspiração e o sombreamento das áreas.

A imagem do infravermelho termal do sensor TIRS/ Landsat-8, contribuíram na identificação, espacialização e compreensão das ilhas de calor na área urbana de Ilha Solteira. A utilização da imagem de satélite Pléiades, com alta resolução espacial, foi fundamental na compreensão das classes de uso e ocupação do solo na formação das ilhas de calor.

Sugere-se aprofundar o estudo sobre a ocorrência de ilhas de calor urbana em cidades de pequeno porte. $\mathrm{O}$ melhor conhecimento desta fenomenologia poderá contribuir para o planejamento urbano, como projetos urbanísticos, que, com manipulação da paisagem urbana, este efeito pode ser amenizado, diminuindo o desconforto térmico, e pequenas diferenças de temperatura podem fazer a diferença para a saúde da população.

\section{REFERÊNCIAS}

BARROS, H.R. \& LOMBARDO, M.A. A ilha de calor urbana e o uso e cobertura do solo em São Paulo-SP. Geousp - Espaço e Tempo, v. 20, p. 160-177, 2016.

CATELANI, C.S.; BATISTA, G.T.; PEREIRA, W.F. Adequação do uso da terra em função da legislação ambiental. In: SIMPÓSIO BRASILEIRO DE SENSORIAMENTO REMOTO, 11, Belo Horizonte. Anais... Belo Horizonte: INPE, 2003. p. 559-566.

COELHO, A.L.N. \& CORREA, W.S.C. Temperatura de Superfície Celsius do Sensor TIRS/Landsat-8: metodologia e aplicações. Revista Geográfica Acadêmica, v. 7, p. 31-45, 2013.

COLTRI, P.P.; VELASCO, G.D.N.; POLIZEL, J.L., DEMETRIO, V.A., FERREIRA, N.J. Ilhas de Calor da estação de inverno da área urbana do município de Piracicaba, SP. 2007. In: SIMPÓSIO BRASILEIRO DE SENSORIAMENTO REMOTO, 13, Florianópolis. Anais...Florianópolis: INPE. 5151-5157.

CORRÊA, P.B.; CANDIDO, L.A.; SOUZA, R.A.F.; ANDREOLI, R.V.; KAYANO, M.T. 2016. Heat Island in Manaus city: study with remote sensing Data, Modeling and Meteorological Data. Revista Brasileira de Meteorologia, v. 31, p. 167-176, 2016

COSTA, D.F.; SILVA, H.R.; PERES, L.F. Identificação de ilhas de calor na área urbana de Ilha Solteira-SP através da utilização de geotecnologias. Engenharia Agrícola, v. 30, p. 974-985, 2010.

EMBRAPA. Mapa pedológico do Estado de São Paulo. Campinas: Engemap. Mapa 13 - Urubupungá, color, $100 \mathrm{~cm} \mathrm{x}$ $70 \mathrm{~cm}$. Escala 1:500.000, 1999.

FERREIRA, L.F.; CARRILHO, S.T.; MENDES, P.C. Áreas verdes urbanas: uma contribuição aos estudos das ilhas de frescor. Brazilian Geographical Journal, v. 6, p. 101-120, 2015.

FIALHO, E.S. Ilha de calor em cidade de pequeno porte: caso de Viçosa, na Zona da Mata Mineira. São Paulo, 2009. Tese (Doutorado) - Faculdade de Filosofia, Letras e Ciências Humanas, Universidade de São Paulo.

GARCÍA, F.F. Manual de climatología aplica: clima, medio ambiente y planificación. Madrid: Editorial Síntesis. 285 p, 1996.
GARTLAND, L. Ilhas de calor: como mitigar zonas de calor em áreas urbanas. São Paulo: Oficina de Textos, 2010.

HERNANDEZ, F.B.T. Análise agroclimática da área de influência do Reservatório da Usina Hidrelétrica de Ilha Solteira, região noroeste do Estado de São Paulo. Ilha Solteira: UNESP, FEPISA e SEAP/PR (Convênio 80/2005). 27 p, 2007.

LIMA, N.R.; PINHEIRO, G.M.; MENDONÇA, F. Clima urbano no Brasil: análise e contribuição da metodologia de Carlos Augusto de Figueiredo Monteiro. Revista Geonorte, v. 3, p. 626-638, 2016.

MASHIKI, M.Y. \& CAMPOS, S. Geoprocessamento aplicado na influência do uso e ocupação do solo na temperatura aparente da superfície no município de Botucatu/SP. Revista Energia na Agricultura, v. 28, p. 143-149, 2013.

MASHIKI, M.Y. Geoprocessamento na identificação de ilhas de calor e influência do uso e ocupação do solo na temperatura aparente da superfície no município de Botucatu/SP. Botucatu, 2012. Dissertação (Mestrado em Agronomia), Universidade Estadual Paulista,.

MIRANDA, E.E.; GOMES, E.G.; GUIMARÃES, M. Mapeamento e estimativa da área urbanizada do Brasil com base em imagens orbitais e modelos estatísticos. Campinas: Embrapa Monitoramento por Satélite, 2005.

ROMERO, C.W. da S. Uso e ocupação do solo em Áreas com Ilhas de Calor na Cidade de Ilha Solteira-SP. Ilha Solteira, 2016. Dissertação (Mestrado em Agronomia), Universidade Estadual Paulista.

SANTANA, E.F.; BATISTA, L.V.; SILVA, R.M. da; SANTOS, C.A.G. Multispectral image unsupervised segmentation using watershed transformation and cross-entropy minimization in different land use. GIScience \& Remote Sensing, v. 51, p. 613 629, 2014

SANTOS, G.R. Identificação de ilhas de calor na área urbana de Ilha Solteira - SP, através de dados orbitais do satélite LANDSAT 5 - TM. Ilha Solteira, 2005. Monografia (Trabalho de Graduação em Agronomia), Universidade Estadual Paulista. SÃO PAULO. Mapa geomorfológico do Estado de São Paulo. São Paulo: IPT (Boletim Técnico Científico, 1), 1981.

SAYDELLES, A. P. Estudo do campo térmico e das ilhas de calor urbano em Santa Maria - RS. Santa Maria. 2005. 
Dissertação (Mestrado em Geografia)-Universidade Federal de Santa Maria.

SILVA, H.R.; ALTIMARE, A.L.; LIMA, E.A.C. de F. Sensoriamento remoto na identificação do uso e ocupação da terra na área do projeto "Conquista da Água", Ilha Solteira - SP, Brasil. Engenharia Agrícola, v. 26, p. 328-334, 2006.

TU, T.; SU, S.; SHYU, H.; HUANG, P.S. Efficient intensity-huesaturation-based image fusion with saturation compensation. Optical Engineering, v. 40, p. 720-728, 2001.

USGS-Geological Survey / Serviço de levantamento geológico americano. Aquisição de imagens orbitais digitais gratuitas do satélite Landsat-8 EUA. http://landsat.usgs.gov. Acesso em: 08 ago. 2015.
VOOGT, J.A. \& OKE, T.R. Thermal remote sensing of urban climates. Remote Sensing of Environment, v. 86, p. 370-384, 2003.

WENG, Q. \& YANG, S. Managing the adverse thermal effects of urban development in a densely populated Chinese city. Journal of Environmental Management, v. 70, p. 145-156, 2004.
Recebido em 10 de setembro de 2019 Aceito em 17 de abril de 2020 